\title{
Estudio de péptidos acarreadores de minerales $y$ antitrombóticos liberados durante la fermentación de leche con Lactobacillus caseiShirota
}

\section{TESIS}

Que para obtener el grado de

Maestro en Biotecnología

\section{PRESENTA}

Ing. Francisco Javier Guzmán Rodríguez

Directora

Dra. Alma Elizabeth Cruz Guerrero

\section{Asesoras}

M. en C. Lorena del Carmen Gómez Ruiz

Dra. María del Carmen Wacher Rodarte 
La Maestría en Biotecnología de la Universidad Autónoma Metropolitana está incluida en el Padrón Nacional de Posgrados de Calidad (PNPC) del CONACyT, con la referencia 001465. 
El jurado designado por la

DIVISIÓN DE CIENCIAS BIOLÓGICAS Y DE LA SALUD DE LA UNIDAD IZTAPALAPA aprobó la tesis:

\title{
Estudio de péptidos acarreadores de minerales y antitrombóticos liberados durante la fermentación de leche con Lactobacillus casei Shirota
}

\author{
Que presentó \\ Ing. Francisco Javier Guzmán Rodríguez
}

COMITÉ TUTORAL

Director:

Dra. Alma Elizabeth Cruz Guerrero.

Asesor:

Dra. María del Carmen Wacher Rodarte.

Asesor:

M. en C. Lorena del Carmen Gómez Ruiz.

Presidente:

JURADO

Dra. María del Carmen Wacher Rodarte Secretario:

Vocal:

Dra. Mariana Gabriela Rodríguez Serrano Vocal:

M. en C. Lorena del Carmen Gómez Ruíz

Dr. Luis Guillermo González Olivares 


\section{AGRADECIMIENTOS}

A mi familia, por darme la vida, por respetar las decisiones que he tomado y por seguir brindándome su apoyo incondicional en todos los sentidos, por tener confianza en mí y recordarme lo mucho que me quieren. Estoy orgulloso de ustedes.

A mi directora de proyecto, la doctora Alma Cruz Guerrero, gran persona y gran investigadora, quien me brindó su confianza, su amistad y quien siempre estuvo al pendiente de mi trabajo. Gracias por su paciencia, por escucharme y permitirme trabajar con usted. Nunca la olvidaré.

A la doctora Gaby, a la maestra Lore y al doctor Mariano quienes compartieron su tiempo, su experiencia y conocimiento. Sus comentarios y observaciones me fueron imprescindibles para el desarrollo de mi proyecto. Gracias por brindarme su amistad y permitirme compartir estos dos años con ustedes.

A Yola que ha sido una de mis mejores amigas, de quien he aprendido mucho no sólo en el laboratorio. Gracias por brindarme tu amistad, tu confianza, tu sabiduría y por ser una fuente de inspiración para mí, me honra ser tu amigo y te voy a extrañar muchísimo (como al pay de queso con zarzamora).

A Alex, Erick, Ruth, Vere, Vivy, Nalle y demás compañeros de la planta piloto 2, con quienes compartí esta segunda casa y de quienes guardo los gratos recuerdos. Gracias por coincidir en espacio y tiempo conmigo.

A Candy, Ruth, Kary, Angélica, Maricoco, Frida, Dany, Alberto, Goyo y mis demás compañeros de generación, aunque nos vemos de vez en cuando recuerdo buenos momentos que pasamos (sufriéndole con Luly). Gracias por su amistad.

A Becky, Karina y Claudia quienes me asesoraron en las técnicas que tanto trabajo me costó montar en laboratorio. Gracias por su tiempo y paciencia.

A Paco Pepe que es un sol, una persona digna de toda mi admiración, una de las personas más comprometidas con su trabajo que conozco.

Al doctor Luis Guillermo González Olivares, a la doctora Carmen Wacher Rodarte y al doctor Héctor Escalona Buendía quienes se tomaron el tiempo de resolver mis dudas para ayudarme a desarrollar este trabajo. Mil gracias.

Bien... en la siguiente página aparece una frase que hace muchos años había marcado en un libro de julio Verne porque me dejó bastante impresionado. Hubo un tiempo en que olvidé estas palabras, así que ahora las comparto a manera de epígrafe para no olvidarlas jamás. 
“La ciencia, hijo mío, está llena de errores; pero de errores que conviene conocer, porque conducen poco a poco a la verdad"

Viaje al centro de la Tierra. Jules Verne 


\section{RESUMEN}

Se evaluó la actividad fijadora de hierro, fijadora de calcio y antitrombótica de leche fermentada con Lactobacillus casei Shirota bajo diferentes condiciones de fermentación. Las fermentaciones se llevaron a cabo aplicando una combinación de $\mathrm{pH}$, temperatura y tiempo de fermentación de acuerdo a un diseño factorial $3 \times 3 \times 2$. Las combinaciones de las condiciones de fermentación que condujeron a una mayor fijación de hierro ( $\mathrm{a}=0.05)$ fueron: a las 12 horas de fermentación, $\mathrm{pH} 6.0 / 42^{\circ} \mathrm{C}, \mathrm{pH}$ 6.25/42 ${ }^{\circ} \mathrm{C}, \mathrm{pH}$ 6.0/39.5 ${ }^{\circ} \mathrm{C}$ y a las 20 horas de fermentación, $\mathrm{pH} 6.5 / 42{ }^{\circ} \mathrm{C}$; con valores de actividad de entre $2.35 \cdot 10^{-4}$ y $4.62 \cdot 10^{-4} \mathrm{mmol}$ de hierro fijado/mg de proteína. En tres de estas cuatro combinaciones destacó la temperatura de $42{ }^{\circ} \mathrm{C}$, reportada como óptima para la actividad de la proteinasa de pared celular de $L b$. casei. La máxima actividad antitrombótica $(\alpha=0.05)$ se encontró con las siguientes combinaciones: a las 12 horas de fermentación, las combinaciones pH 6.0/39.5 ${ }^{\circ} \mathrm{C}$, $\mathrm{pH} 6.25 / 37^{\circ} \mathrm{C}, \mathrm{pH} 6.5 / 37^{\circ} \mathrm{C}$, y a las 20 horas de fermentación, las combinaciones $\mathrm{pH}$ 6.25/37 ํㅡ y pH 6.5/42 ํㅜ; con porcentajes de inhibición de entre 67.6 y $134.0 \%$ de inhibición de coágulo/mg de proteína respectivamente. Se observó la influencia de la temperatura como factor independiente, con un máximo de actividad antitrombótica a $39.5 \mathrm{C}$, únicamente cuando el $\mathrm{pH}$ fue de 6.0 , tanto a 12 como a 20 horas de fermentación. No se encontró influencia $(\alpha=0.05)$ sobre la actividad fijadora de calcio con ninguno de los tratamientos estudiados. 


\begin{abstract}
Iron binding activity, calcium binding activity, and antithrombotic activity were evaluated in milk fermented with Lactobacillus casei Shirota under different fermentation conditions. Fermentations were carried out by applying a combination of $\mathrm{pH}$, temperature and fermentation time according to a factorial design $3 \times 3 \times 2$. The highest iron binding activity $(\alpha=0.05)$ was observed when fermentation conditions were: $\mathrm{pH} 6.0 / 42{ }^{\circ} \mathrm{C}, \mathrm{pH} 6.25 / 42{ }^{\circ} \mathrm{C}, \mathrm{pH} 6.0 / 39.5^{\circ} \mathrm{C}$, at 12 hours and $\mathrm{pH} 6.5 / 42{ }^{\circ} \mathrm{C}$, at 20 hours. The values of the iron-binding activity ranged between $2.35 \cdot 10^{-4}$ and $4.62 \cdot 10^{-4} \mathrm{mmol}$ of bonded iron per $\mathrm{mg}$ of protein. In three of these four combinations noted the temperature of $42^{\circ} \mathrm{C}$, reported as optimal for the activity of cell envelope proteinasa of $L b$. casei. Maximum antithrombotic activity $(\alpha=0.05)$ was found with next combinations: $\mathrm{pH} 6.0 / 39.5{ }^{\circ} \mathrm{C}, \mathrm{pH} 6.25 / 37^{\circ} \mathrm{C}, \mathrm{pH} 6.5 / 37^{\circ} \mathrm{C}$, at 12 hours of fermentation and, $\mathrm{pH} 6.25 / 37^{\circ} \mathrm{C}$ and $\mathrm{pH} 6.5 / 42{ }^{\circ} \mathrm{C}$, at 20 hours of fermentation. Anticoagulant activity ranged from 67.6 and $134.0 \%$ of clot inhibition per $\mathrm{mg}$ de protein, respectively. The influence of temperature was studied as an independent factor. Highest antithrombotic activity was observed at $39.5^{\circ} \mathrm{C}$, only when the $\mathrm{pH}$ was 6.0 , both at 12 and 20 hours of fermentation. No influence was found $(\alpha=0.05)$ on the calcium binding activity with any of the treatments.
\end{abstract}


ÍNDICE

1 INTRODUCCIÓN _ _ _ 1

2 ANTECEDENTES _ 3

2.1 Péptidos bioactivos __ 3

2.2 Funciones de los péptidos bioactivos

2.2.1 Péptidos con actividad acarreadora de minerales __ 4

2.2.2 Péptidos con actividad antitrombótica ___ 6

2.3 Producción de péptidos bioactivos___ 7

2.3.1 Digestión gastrointestinal ___ 8

2.3.2 Digestión in vitro ___ 8

2.3.3. Fermentación por bacterias ácido lácticas ___ 8

2.4 Factores de la fermentación que influyen en la producción de péptidos bioactivos __ 9

2.5 Las bacterias ácido lácticas (BAL) _ 10

2.6 Sistema proteolítico de las bacterias ácido lácticas ___ 11

2.6.1 Proteinasas ligadas a la pared celular (CEP)___ 12

2.6.2 Diferencias y similitudes entre las CEP de distintas especies y cepas ___ 12

2.6.3 Especificidad de la proteólisis ___ 13

2.6.4 Influencia de la secuencia de aminoácidos en el sustrato ___ 13

2.6.5 Posición y tipo de aminoácidos en los péptidos liberados__ 14

2.6.6 Factores del proceso que influyen en la actividad y especificidad de la CEP ___ 15

a) Tiempo de fermentación _ـ 15

b) Condiciones de incubación $\mathrm{pH}$ y temperatura $(\mathrm{T})$

c) Otros factores _ـ 17

2.7 Lactobacillus casei___ 17

3 JUSTIFICACIÓN _ _ 20

4 OBJETIVOS _ _ 21 21

4.1 Objetivo General ___ 21

4.2 Objetivos Particulares ___ 21

5 HIPÓTESIS _ 21

6. DISEÑO DE ESTUDIO _ _ 22

7 Metodología __ 23

7.1 Microorganismo _ 23

7.2 Fermentación de la leche ___ 23

7.3 Recuento en placa ___ 24

7.4 Determinación de actividad fijadora de calcio ___ 24

7.5 Obtención del extracto libre de células (ELC) _ 25 
7.6 Determinación de actividad fijadora de hierro 25

7.7 Determinación de actividad antitrombótica 26

7.8 Determinación de proteínas 27

7.9 Tratamiento estadístico 28

8 RESULTADOS Y DISCUSIÓN 29

8.1 Determinación de curvas de crecimiento de Lactobacillus casei Shirota 29

8.2 Actividad fijadora de hierro 30

8.3 Actividad antitrombótica 36

8.4 Actividad fijadora de calcio 44

9 CONCLUSIONES 47

10 Perspectivas 48

11 REFERENCIAS 49 


\section{INTRODUCCIÓN}

Durante la digestión de los alimentos, las proteínas son hidrolizadas en fragmentos pequeños llamados péptidos, con la finalidad de que puedan ser absorbidos en el intestino.

La mayoría de los péptidos cumplen con una función exclusivamente nutrimental, es decir, un aporte energético y de aminoácidos, sin embargo algunos de ellos poseen funciones adicionales benéficas a la salud, por lo que son denominados bioactivos.

Las funciones de estos péptidos sólo se manifiestan cuando son liberados de las proteínas, en donde se encuentran encriptados.

Las proteínas de la leche, el huevo y algunas proteínas de la carne han sido las más estudiadas por la liberación de estos péptidos. Las funciones que desempeñan son amplias: antitrombóticos, antihipertensivos, acarreadores de minerales, opiáceos, inmunomoduladores, etc.

La liberación de estos péptidos puede darse por tres vías. La primera, es durante la digestión, gracias a la acción de las enzimas proteolíticas secretadas en el tracto intestinal, como son tripsina, quimotripsina, pepsina, etc. Una segunda posibilidad es la digestión in vitro utilizando enzimas proteolíticas. La tercer alternativa para su obtención es mediante procesos de fermentación, por ejemplo con bacterias ácido lácticas, capaces de hidrolizar las proteínas de la leche gracias a su sistema proteolítico, para obtener los aminoácidos necesarios para su crecimiento. Algunas de las bacterias ácido lácticas son consideradas como probióticos pues al ser ingeridos promueven beneficios en la salud, ya que son capaces de resistir el proceso digestivo y colonizar el intestino, donde previenen la estancia de bacterias patógenas al competir con ellas por los sitios de adhesión en el tracto intestinal.

Dentro de estas bacterias probióticas, se encuentra Lactobacillus casei, una bacteria Gram-positiva, no mótil, no esporulada, catalasa negativa, cuyas células son bastones de 0.7-1.1 $\times$ 2.0-4.0 $\mu \mathrm{m}$, y tiende a formar cadenas. Es frecuente encontrarla en productos lácteos fermentados, el tracto intestinal humano, boca y vagina. Se ha demostrado su utilidad tanto en la prevención y tratamiento de la 
diarrea como en el estímulo la respuesta inmune del intestino.

Se ha encontrado que algunas cepas de $L b$. casei producen péptidos bioactivos a partir de las proteínas de la leche durante la fermentación, entre estas cepas se encuentran $L b$. casei Shirota que ha sido estudiada por la producción de péptidos antitrombóticos y antihipertensivos.

En este trabajo se estudió la capacidad antitrombótica y acarreadora de minerales de péptidos liberados durante la fermentación de leche con $L b$. casei Shirota, bajo diferentes condiciones de proceso. 


\section{ANTECEDENTES}

\subsection{PÉptidos BioActivos}

El valor de las proteínas de alimentos (leche, carne, huevo y productos vegetales) como fuente esencial de aminoácidos está bien documentada, pero recientemente se ha reconocido que ejercen otras funcionalidades in vivo. De ahí que reciban una creciente atención como ingredientes de alimentos funcionales enfocados hacia el control de las enfermedades crónicas relacionadas con la dieta. Algunas de éstas son las enfermedades cardiovasculares, diabetes tipo II y obesidad. Es por ello que el interés se ha enfocado en el estudio de los péptidos bioactivos derivados de las proteínas de los alimentos (Korhonen, 2009).

Los péptidos bioactivos, han sido estudiados desde 1979, y se definen como fragmentos específicos de las proteínas. Estos fragmentos son inactivos al permanecer encriptados dentro de su estructura, pero una vez liberados, realizan diversas funciones en el organismo y pueden influenciar la salud humana. Dentro de estas funciones se ha demostrado tanto in vitro como in vivo, que tienen influencia sobre los sistemas digestivo, endócrino, cardiovascular, inmune y nervioso (Erdmann y col., 2008; Korhonen, 2009).

\subsection{FUNCIONES DE LOS PÉPTIDOS BIOACTIVOS}

Dentro de las funciones encontradas en los péptidos con actividad biológica, destacan los inhibidores de la enzima convertidora de la angiotensina (ACE), antitrombóticos, acarreadores de minerales, antioxidantes, inmunomoduladores, opioides entre otros. Asimismo existen aquellos con propiedades inhibitorias de propil endopeptidasas y péptidos tóxicos celiacos, los cuales influyen de manera negativa en la salud (Torres-Llanez y col., 2005; Guesdon y col., 2006; Iwaniak y Minkiewicz, 2008; Erdmann y col., 2008; y González-Olivares y col., 2011). 
La aplicación de péptidos para propósitos terapéuticos, especialmente en el tratamiento del cáncer, de infecciones, de desórdenes del sistema inmunológico y de desórdenes cardiovasculares es actualmente el foco de interés de muchos grupos de investigación (Iwaniak y Minkiewicz, 2008).

La potencia de estos péptidos es menor a la de los fármacos (Torres-Llanez y col., 2005), pero los productos que mantienen una bioactividad moderada, se comportan intrínsecamente como alimentos funcionales y pueden ser fácilmente incluidos en la dieta (Silva y Malcata, 2005).

\subsubsection{PÉPtidos CON ACTIVIDAD ACARREADORA DE MINERALES}

Los iones metálicos juegan un papel en la mayoría de los procesos metabólicos, por ejemplo, como activadores de algunas reacciones y en el control de la óxidoreducción (Dimitrov, 2009). Entre los iones metálicos divalentes, el calcio juega el papel más importante, al proveer rigidez a la estructura ósea del ser humano, y actuar como mensajero secundario en numerosos eventos intracelulares, tomando ventaja de su gran gradiente de concentración en la membrana. La mayor cantidad de calcio que consumimos proviene de la leche y sus productos, aún así la deficiencia de este metal en la dieta causa osteoporosis, por lo que suplementos de calcio en la dieta son algunas veces necesarios. Para incrementar su biodisponibilidad, es importante considerar no sólo la cantidad ingerida sino también las sustancias que coexisten con él. (Guangrong y col., 2011).

Algunos péptidos derivados de la digestión intestinal de $\alpha s_{1}$-caseína $\left(\alpha s_{1}-C N\right)$ y $\beta$ caseína $(\beta-C N)$, conocidos como fosfopéptidos de caseína (CPP), pueden tener un efecto potencial en la absorción de calcio y magnesio a través de la barrera intestinal. Éstos usualmente son péptidos pequeños que contienen serina fosforilada; estos péptidos tienen un alto contenido de cargas negativas. Estas cargas negativas permiten ligar fuertemente cationes divalentes ( $\mathrm{Fe}, \mathrm{Mg}, \mathrm{Mn}, \mathrm{y} \mathrm{Cu}$ ), con la formación de complejos solubles. Al formar estos complejos solubles se evita la precipitación de sales insolubles; en consecuencia, incrementan la concentración y disponibilidad de 
los minerales en el medio y promueven su absorción a través de la mucosa intestinal (Dimitrov, 2009). Adicionalmente, las cargas negativas hacen que los CPP se vuelvan resistentes a hidrólisis posterior (Erdmann y col., 2008; Guangrong y col., 2011).

Además de la serina existen otros residuos capaces de fosforilarse como treonina y tirosina y se ha sugerido que otros aminoácidos, tal como los ácidos glutámico y aspártico pueden contribuir a la unión a iones metálicos (Dimitrov, 2009).

Por otro lado las proteínas del suero presentan en su estructura péptidos con propiedades acarreadoras de minerales. Las proteínas del suero tienen la habilidad de ligar cationes di y trivalentes, un atributo que podría ser usado para promover la biodisponibilidad del hierro en pacientes anémicos. Recientemente, la lactoferricina, un péptido derivado de la hidrólisis péptica del suero, demostró tener capacidad de ligar hierro. Tales péptidos pueden ayudar en la prevención de anemia, una deficiencia nutricional ampliamente distribuida en niños y mujeres (Kim y col., 2004). Para la liberación de péptidos se han utilizado enzimas proteolíticas como pepsina, alcalasa, papaína, las cuales han sido empleadas para la hidrólisis de proteínas de leche. Sin embargo, enzimas de diferentes orígenes pueden variar en su capacidad de hidrolizar proteínas del suero y esto puede influenciar las características fisicoquímicas de los hidrolizados y su habilidad de ligar hierro (Kim y col., 2004).

Las bacterias ácido lácticas son capaces de liberar CCP de las proteínas de la leche. Dimitrov (2009) reportó que las cepas con la mayor actividad proteolítica mostraron tener la mayor actividad fijadora de calcio después de la proteólisis. Los derivados proteolíticos de Lb. casei y Lb. helveticus presentaron la mayor bioactividad. Lb. casei C3 liberó el péptido que corresponde al fragmento (f 15-20) de la $\beta-C N$. Mientras que otros CPP producidos por BAL y encontrados en caseínas son los correspondientes a los fragmentos (f 1-25), (f 1-28) y (f 2-28) de $\beta-C N$; los fragmentos (f 43-58), (f 45-55), (f 59-79), (f 66-74) y (f 106-119) de $\alpha_{s_{1}}-\mathrm{CN}$, entre otros (Silva y Malcata, 2005). 


\subsubsection{PÉPTIDOS CON ACTIVIDAD ANTITROMBÓTICA}

La coagulación sanguínea es el mecanismo más importante para prevenir la pérdida de sangre después de un daño tisular. La agregación plaquetaria es el paso más importante en este proceso. El fibrinógeno tiene un papel bifuncional, pues participa tanto en la formación de fibrina como en la agregación de plaquetas. En este último caso su papel es mediado por su unión a receptores plaquetarios estimulados por ADP y calcio, de este modo, el principal sitio de interacción entre fibrinógeno y plaquetas, se encuentra en un dodecapéptido de la cadena $\mathrm{Y}$ del fibrinógeno (HHLGGAKQAGDV), ubicado en su extremo C-terminal (residuos del 400 al 411) (Jollès y col., 1986; Rutherfurd y Gill, 2000; Erdmann y col., 2008).

La trombosis, se desarrolla por anormalidades en la coagulación, las cuales pueden deberse a la hiperreactividad de las plaquetas, a altos niveles de proteínas homeostáticas (fibrinógeno), fibrinólisis defectuosa e hiperviscosidad de la sangre. Por ello algunos fármacos son empleados para inhibir la agregación plaquetaria y promover la fibrinólisis. Se han reportado similitudes a nivel molecular entre la coagulación sanguínea (interacción entre fibrinógeno y trombina) y la coagulación de la leche (interacción entre k-CN y quimosina). El estudio de estas homologías ha llevado a encontrar ciertos péptidos que cumplen con funciones antitrombóticas (Jollès y col., 1986; Erdmann y col., 2008).

Estos péptidos son usados para reducir la agregación de plaquetas. Un péptido antitrombótico derivado de la k-CN, llamado casoplatelina, es el undecapéptido MAIPPKKNQDK (residuos 106-116) que actúa: (i) inhibiendo la agregación de plaquetas activadas por ADP e (ii) inhibiendo la unión de estas plaquetas al dodecapéptido de la cadena $\mathrm{y}$ del fibrinógeno (Jollès y col., 1986). Lo anterior es comprensible debido a que el péptido MAIPPKKNQDK tiene tres aminoácidos importantes, isoleucina (I), lisina $(\mathrm{K})$ y ácido aspártico (D), ubicados en posición homóloga a la cadena $\mathrm{y}$ del fibrinógeno humano (HHLGGAKQAGDV), con quien compite como sustrato para la trombina (Jollès y col., 1986). 
Se cree que los péptidos antitrombóticos derivados de la leche se absorben intactos en la sangre, pues se han encontrado en concentraciones fisiológicamente activas en el torrente sanguíneo de recién nacidos tras la ingestión de leche materna o fórmula láctea (Erdmann y col., 2008).

Un tetrapéptido antitrombótico de importancia menor es el péptido de secuencia KRDS de la lactoferrina, el cual guarda similitudes con el péptido RGDS de la cadena $\alpha$ del fibrinógeno. También se han reportado las fracciones (f 103-111), ( $f$ 106-112) y (f 113-116) de la k-CN (Jollès y col., 1986; Rutherfurd y Gill, 2000; Silva y Malcata, 2000; Erdmann y col., 2008).

Rojas-Ronquillo y col. (2012) estudiaron la generación de péptidos con propiedades antihipertensivas y antitrombóticas liberados durante la fermentación de caseína con Lb. casei Shirota y se determinó el comportamiento de la bioactividad en el transcurso de la fermentación, encontrándose a las 27 h un $80.7 \%$ de inhibición de trombina. Uno de los péptidos identificados, provino de la $\beta$-caseína, con la secuencia YQEPVLGPVRGPFPIIV.

\subsection{PRODUCCIÓN DE PÉPTIDOS BIOACTIVOS}

Los péptidos bioactivos son obtenidos mediante la hidrólisis de las proteínas por tres vías: (i) digestión gastrointestinal, (ii) digestión in vitro con proteasas gástricas, y (iii) proteólisis mediada por enzimas de bacterias ácido lácticas (BAL) (Silva y Malcata, 2005; Guo y col., 2009; Korhonen, 2009).

Diversos estudios han demostrado que el nivel de bioactividad y biodisponibilidad de algunos péptidos liberados por fermentación están relacionados con el crecimiento del microorganismo y el grado de hidrólisis de sus proteínas de origen, sin embargo, lo anterior no es una regla general, pues con un tiempo de incubación extendido, e incluso durante el almacenamiento en frío, algunos péptidos se hidrolizan dando origen a otros que no presentan bioactividad (Fuglsang y col., 2003; Silva y Malcata, 2005; Ong y col., 2007; Korhonen, 2009; Guo y col., 2009; Dimitrov, 2009; Nielsen y col., 2009; Pihlanto y col., 2010; Gonzalez-Gonzalez y col., 2011). 


\subsubsection{DigeSTIÓN GASTROINTESTINAL}

La primera vía mencionada ocurre de manera natural por una digestión in vivo, pues durante la digestión gastrointestinal, pequeños péptidos pueden ser liberados por acción de las proteasas secretadas en el sistema digestivo (pepsina, tripsina, etc.) (Iwaniak y Minkiewicz, 2008).

\subsubsection{DIGESTIÓN IN VITRO}

La segunda vía representa la manera más común de producir péptidos bioactivos, esta es a través de la hidrólisis completa de las proteínas por las enzimas digestivas en ensayos in vitro. Las enzimas más utilizadas han sido pepsina, tripsina y quimotripsina que han demostrado liberar un gran número de péptidos con diversas actividades. Otras enzimas que han sido utilizadas para este fin son termolisina y proteinasa k. En el caso de la tripsina, se producen principalmente péptidos inhibidores de la ACE y fosfopéptidos fijadores de calcio (Korhonen y Pihlanto, 2006; Korhonen, 2009; Guo y col., 2009).

\subsubsection{FERMENTACIÓN POR BACTERIAS ÁCIDO LÁCTICAS}

En el tercer caso la proteólisis es llevada a cabo por microorganismos. Muchos cultivos iniciadores tienen una relativamente alta capacidad proteolítica y la formación de péptidos bioactivos puede esperarse durante la manufactura de los productos lácteos fermentados. De hecho, la liberación de diferentes péptidos bioactivos de las proteínas de la leche durante la proteólisis microbiana ha sido muy estudiada (Korhonen, 2009).

El tipo de lácteo, la tecnología adaptada y la selección de cepa basada en la especificidad de la proteólisis, son factores que determinan la generación por proteólisis de péptidos bioactivos.

Por ejemplo, Ong y col. (2007), elaboraron queso Cheddar donde uno de los adjuntos en el cultivo iniciador fue un probiótico, y observó que el queso control y el que contenía el probiótico, tuvieron un perfil de péptidos muy similar, pero la actividad 
inhibidora de ACE fue mayor en el aquel que contenía el probiótico.

\subsection{FACTORES DE LA FERMENTACIÓN QUE INFLUYEN EN LA PRODUCCIÓN DE PÉPTIDOS BIOACTIVOS}

Uno de los factores que influye en la producción de péptidos con actividad biológica es la especie microbiana y la cepa involucrada en la fermentación. Por ejemplo, han sido varias las especies estudiadas por la capacidad de sus hidrolizados de inhibir la actividad de la ACE, la más estudiada de ellas es $L b$. helveticus, la cual se encuentra en un producto comercial con propiedades antihipertensivas (Korhonen, 2009). Lb. helveticus es reconocida por ser una de las BAL que más inhiben la actividad de la ACE (Fuglsang y col., 2003; Ahn y col., 2009; Sadat-Mekmene y col., 2011).

Otros ejemplos de bacterias productoras de estos péptidos son $L b$. paracasei, $L b$. brevis, Lb. casei, etc. (Ahn y col., 2009; Pihlanto y col., 2010).

Las condiciones bajo las cuales se lleva a cabo la fermentación, como son la temperatura, el $\mathrm{pH}$, tiempo de incubación, la cantidad de inóculo empleado, etc. tienen influencia sobre la actividad biológica de las leches fermentadas (Guo y col., 2009; Pan y col., 2010).

El perfil de péptidos en los hidrolizados va cambiando en función del tiempo, de ahí que la actividad biológica sea dependiente del tiempo de incubación, y por lo tanto de la fase de crecimiento del microorganismo. Por ejemplo, la mayor tasa de actividad inhibitoria de ACE en la leche fermentada, se encuentra entre la fase exponencial y la fase estacionaria, y este tiempo varía dependiendo la especie microbiana. Una vez pasado este periodo, la actividad inhibitoria de ACE va disminuyendo (Ramachandran y Shah, 2008; Pan y col., 2010; Gonzalez-Gonzalez y col., 2011).

Ramachandran y Shah (2008), estudiaron los péptidos inhibidores de la ACE, producidos por $L$ b. casei 15286, y encontraron la máxima actividad entre 3 y 6 horas de incubación. Pan y col. (2010), estudiaron Lb. helveticus LB10, y la encontraron entre 4 y 20 horas. Pihlanto y col. (2010) estudiaron Lb. casei y encontraron un incremento de actividad inhibitoria tras 8 horas de incubación, y una alta actividad después de 24 horas. 
La temperatura a la cual se lleva a cabo la fermentación tiene influencia no sólo sobre el crecimiento bacteriano, sino también sobre la producción de péptidos bioactivos. Guo y col. (2009) estudiaron la liberación de péptidos de suero de leche hidrolizado por la proteinasa de $L b$. helveticus y reportan un óptimo de liberación de éstos péptidos a $39^{\circ} \mathrm{C}$.

En algunos casos, la actividad biológica de los péptidos puede aumentar lentamente durante el almacenamiento en refrigeración de los productos fermentados debido a una hidrólisis adicional de los péptidos y polipéptidos previamente generados (Nielsen y col., 2009).

Con respecto a la influencia del pH, Pan y col., (2010) encontraron que a un pH inicial de 7.5 durante la fermentación de la leche se favorece una alta actividad inhibidora de ACE del hidrolizado.

Gonzalez-Gonzalez y col. (2011), señalan que la relación del pH con la actividad inhibitoria de la ACE depende de la cepa y los péptidos liberados.

El calcio iónico liberado durante la fermentación de la leche puede aumentar o inhibir la bioactividad de algunos péptidos, dependiendo de su concentración (GonzalezGonzalez y col., 2011), sin embargo, la mayoría de los reportes apuntan a que la presencia del calcio así como otros cationes (magnesio, potasio) favorece la reducción de la presión arterial (Fuglsang y col., 2003; López-Fandiño y col., 2006; Pihlanto y col., 2010).

\subsection{LAS BACTERIAS ÁCIDO LÁCTICAS (BAL)}

Las BAL son microorganismos Gram positivos, catalasa negativos, no esporulados, anaerobios facultativos $y$ fermentadores. Las BAL tienen gran importancia tecnológica, pues se emplean como cultivos iniciadores de diferentes productos lácteos (Boutrou y col., 2001). Los lactococos son las BAL primordialmente usados como cultivos iniciadores, sin embargo los lactobacilos han cobrado importancia, pues colonizan el queso durante las últimas etapas de la fermentación alcanzando altas densidades y contribuyendo a la proteólisis y desarrollo de sabores (Fernández 
de Palencia y col., 1997).

Algunas BAL son consideradas como probióticos, los cuales son microorganismos no patógenos, la mayoría de ellos de origen humano, los cuales confieren un beneficio a la salud del huésped y son capaces de prevenir o ayudar en el tratamiento de algunas enfermedades cuando son administrados en cantidades adecuadas. Ejemplos de BAL con función probiótica son $L b$. casei, Lb. jhonsonii, y Bifidobacterium bifidus (Figueroa-González y col., 2011).

Entre los beneficios a la salud por parte de las BAL probióticas se encuentran el estimular el sistema inmune como auxiliares en la prevención y tratamiento de la diarrea y como auxiliares en el tratamiento de enfermedades inflamatorias del intestino. Al modificar la flora intestinal, influyen en el estado de salud a través de la producción de vitaminas, ácidos grasos de cadena corta, degradando sustancias químicas no digeridas, estimulando la respuesta inmune y brindando protección frente a patógenos (Ogawa y col., 2001; González-Olivares y col., 2011; Hickson, 2011). Es difícil indicar los mecanismos de acción en los probióticos porque cada especie y variedad tienen mecanismos específicos de protección contra patógenos (Hartmann y Meisel, 2007; Yoon y Sun, 2011; Ghassem y col., 2011).

\subsection{SISTEMA PROTEOLÍTICO DE LAS BACTERIAS ÁCIDO LÁCTICAS}

La habilidad de las BAL de crecer en leche depende de la disponibilidad de péptidos y aminoácidos libres, fuentes exógenas de nitrógeno necesarias para su crecimiento óptimo. Sin embargo las concentraciones de estos componentes en forma libre, en la leche, son bajas y la capacidad de síntesis de aminoácidos de las BAL son limitadas, debido a lo anterior, las BAL necesitan contar con un sistema proteolítico que le permita liberar péptidos y aminoácidos de las proteínas de la leche (Kojic y col., 1991; Juillard y col., 1995; Meijer y col., 1996; Fuglsang y col., 2003; Ramachandran y Shah, 2008; Guo y col., 2009; Gonzalez-Gonzalez y col., 2011).

Los sistemas proteolíticos de las BAL consisten en (i) proteinasas de pared celular (CEP), que están involucradas en el primer paso de degradación de la caseína con 
especificidad muy general, (ii) sistemas de transporte que introducen los oligopéptidos a la célula, y (iii) peptidasas intracelulares (Juillard y col., 1995; Manso y col., 2005; Torres-Llanez y col., 2005; Ramachandran y Shah, 2008; Otte y col., 2011; Rojas-Ronquillo y col., 2012).

\subsubsection{Proteinasas ligadas a La PAREd CELULAR (CEP)}

Las CEP son proteinasas que muestran homología de secuencia con la familia de las serina-proteasas tipo subtilisina (Fernández de Palencia y col., 1997).

Diferentes pesos moleculares son reportados para las proteinasas purificadas de las BAL. Fernández de Palencia y col. (1997) reportaron una CEP de Lb. helveticus con un peso molecular de $45 \mathrm{kDa}$ mientras que Fuglsang y col. (2003) reportaron pesos moleculares de hasta $212 \mathrm{kDa}$. Las CEP de la mayoría de las BAL son liberadas incubando células en una solución amortiguadora libre de calcio (Kojic y col., 1991; Fernández de Palencia y col., 1997), sin embargo para liberar las enzimas fuertemente adheridas a la pared celular, como las de $L b$. casei IFPL 731, no es suficiente el lavado con esta solución amortiguadora, sino que además son necesarios agentes quelantes como EDTA (Fernández de Palencia y col., 1997).

\subsubsection{DIFERENCIAS Y SIMILITUDES ENTRE LAS CEP DE DISTINTAS ESPECIES Y CEPAS}

Pueden existir variantes de la proteinasa dentro de una misma especie. En estos casos, los aminoácidos en el sitio de unión parecen ser diferentes a pesar de que las CEP estudiadas pertenecen a la misma familia (serina-proteasas). Las diferencias observadas en la especificidad de las CEP se deben solamente a la variación en la secuencia de muy pocos aminoácidos (Fernández de Palencia y col., 1997; Fernandez-Espla y col., 2000; Sadat-Mekmene y col., 2011).

Algunas especies que presentan esta variedad de proteinasas son $L b$. helveticus (que presenta las CEP $\mathrm{PrtH}_{1}$ y $\mathrm{PrtH}_{2}$ ) y Lb. casei (Sadat-Mekmene, 2011).

Algunas diferencias entre las diversas CEP de $L b$. casei, son establecidas en función de su preferencia por determinadas proteínas y de sus condiciones óptimas de actividad, por ejemplo la proteinasa de $L b$. casei HN14, sólo hidroliza $\beta-C N$ y sus 
condiciones óptimas son $30^{\circ} \mathrm{C}$ y pH de 7.2 (Kojic y col., 1991), mientras que la proteinasa de $L b$. casei IFPL 731 hidroliza preferentemente a la $\beta-C N$ (y más lentamente a $\alpha_{1}-\mathrm{CN}$ ) y presenta su máxima actividad a $40{ }^{\circ} \mathrm{C}$ y $\mathrm{pH}$ de 6.0 (Fernández de Palencia y col., 1997).

\subsubsection{ESPECIFICIDAD DE LA PROTEÓLISIS}

Las proteinasas de pared celular producidas por BAL mesófilas, atacan preferentemente a las caseínas, con marcada preferencia por la $\beta-C N$. Un sistema de clasificación de las CEP se basa en la especificidad hacia una fracción de $\alpha_{1}-\mathrm{CN}$ que comprende los residuos que van del 1 al 23. Bajo este criterio las CEP pueden clasificarse en tres tipos: i) proteinasas $P_{l}$, que muestran mayor afinidad por $\beta-C N$ y un poco por $\mathrm{k}-\mathrm{CN}$, ii) proteinasas $\mathrm{P}_{\mathrm{III}}$, con afinidad hacia $\beta$ y $\mathrm{k}-\mathrm{CN}$, con especificidad de enlaces diferentes, y además pueden catalizar la hidrólisis de $\alpha_{1}{ }_{1}-\mathrm{CN}$, y finalmente iii) proteinasas $P_{1 / I I I}$, las cuales presentan características intermedias, hidrolizando a $\beta-C N$ y as $_{1}$ (Exterkate y col., 1993; Fernandez de Palencia y col., 1997; Reid y Coolbear, 1998; Fernandez-Espla y col., 2000; Sadat-Mekmene y col., 2011).

\subsubsection{INFLUENCIA DE LA SECUENCIA DE AMINOÁCIDOS EN EL SUSTRATO}

Una misma fracción de caseína puede ser escindida en varios sitios produciendo gran diversidad de péptidos durante la fermentación (Fuglsang y col., 2003; Pihlanto y col., 2010).

Juillard y col. (1995), reportaron que el 44\% de los enlaces peptídicos (91 sitios de ruptura) de $\beta-C N$ fueron hidrolizados por la PrtP de Lactococcus lactis MG611, dando lugar a más de 100 oligopéptidos. Es por ello que algunos autores han llegado a señalar que el sitio de hidrólisis en las caseínas ocurre sin importar el tipo de aminoácidos presentes (Sadat-Mekmene y col., 2011).

Sin embargo, y pese a esta especificidad tan general, se han llegado a encontrar ciertos enlaces en la estructura de las caseínas, que ya han sido identificados como sitios específicos de hidrólisis para los diferentes tipos de CEP. Por ejemplo la PrtS 
de Streptococcus thermophilus hidroliza los enlaces $1-9$ y $9-10$ de la $\alpha_{1}-C N$, lo cual es característico de las CEP-P. Éste patrón de hidrólisis es dependiente del pH del medio, por un rearreglo del sitio activo de la PrtS. (Fernandez-Espla y col., 2000). En el caso de $\beta-C N$, las CEP parecen tener preferencia por la hidrólisis de la parte Cterminal y los enlaces del fragmento (f60 - 105), así como por el enlace Leu ${ }^{192}$ Tyr $^{193}$ (Juillard y col., 1995; Boutrou y col., 2001).

Se ha observado también, que algunos enlaces hidrolizados difieren cuando la hidrólisis es llevada a cabo in vitro (con una proteinasa actuando sobre una caseína pura), y cuando se lleva a cabo in situ (en un producto fermentado donde interactúan diferentes caseínas y enzimas). Lo anterior puede sugerir: i) la intervención de otras proteasas (exopeptidasas lactococales, catepsinas) que pudieron haber removido uno o dos aminoácidos del extremo terminal de los péptidos, y ii) factores como $\mathrm{pH}$, $\mathrm{T}, \mathrm{a}_{\mathrm{w}}$, hidrofobicidad, sales, afectan la especificidad de la CEP sobre caseínas intactas, de manera que en un sistema tan complejo como la leche puede modificarse la especificidad (Boutrou y col., 2001).

Así como se han identificado ciertos enlaces que son hidrolizados preferentemente por la CEP, se han identificado aquellos que no lo son, esto se hace evidente por la ausencia de péptidos provenientes de estos enlaces, en estudios in situ, debido tal vez a que dichos enlaces forman parte de la estructura de la matriz de caseínas de la cuajada. Ejemplos de estos enlaces son los fragmentos $\beta-C N$ (110-170), para-K$\mathrm{CN}, \alpha_{1}-\mathrm{CN}(60-120), \alpha_{1}-\mathrm{CN}(131-199)$ y as 2 -CN (30-110) (Boutrou y col., 2001).

\subsubsection{POSICIÓN Y TIPO DE AMINOÁCIDOS EN LOS PÉPTIDOS LIBERADOS}

Se han estudiado las características de los péptidos liberados por acción de la CEP a fin de encontrar reglas o patrones comunes en la proteólisis efectuada por estas enzimas. En estos estudios se ha observado que la especificidad de la hidrólisis está influenciada por el tipo de aminoácidos presentes en ciertas posiciones de los péptidos liberados, debido a la carga de estos residuos y a sus características de hidrofobicidad (Fernandez-Espla y col., 2000). 
La posición de los aminoácidos en los extremos $\mathrm{N}$ y $\mathrm{C}$ de los péptidos liberados están indicados como $\mathrm{PX}$ y $\mathrm{P}$ 'X respectivamente, donde $\mathrm{X}$ es la distancia en número de residuos del sitio de ruptura (Juillard y col., 1995).

Un efecto positivo en la ruptura fue hallado en la posiciones: P6 (Asp, Arg, His), P4 (Asp, Ala, Phe, Tyr), P'1 (Asp, Thr, Ala, Tyr). Cuando Ala y Tyr se encontraron en las posiciones $\mathrm{P} 4$ y $\mathrm{P} 1$ respectivamente, siempre hubo hidrólisis. Cuando Asn o Arg se encontraron en la posición P'2 no hubo hidrólisis. Igualmente un fuerte efecto negativo fue identificado cuando Phe y Glu se encontraron en posiciones P6 y P1 (Juillard y col., 1995).

Además del aminoácido también se buscó una relación del tipo de aminoácido con respecto a la hidrólisis: en la posición P2 los aminoácidos hidrofóbicos tienen un efecto positivo en la ruptura, por el contrario los aminoácidos hidrofílicos tienen un efecto negativo en la misma posición. Además los residuos hidrofóbicos en posiciones P4, P3 y P'2 así como los neutros en P4 tuvieron una baja frecuencia de hidrólisis (Juillard y col., 1995).

Once enlaces peptídicos (Asn ${ }^{68}-\operatorname{Ser}^{69}$, Gln $^{141}-\operatorname{Ser}^{142}$, Leu ${ }^{163}-\operatorname{Ser}^{164}$, Leu $^{165}-\operatorname{Ser}^{166}$,

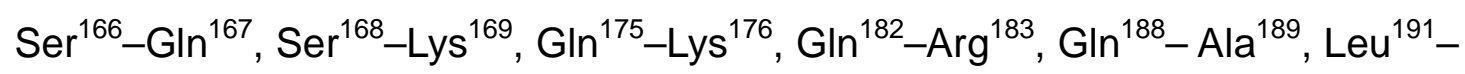
Leu $^{192}$, and $\mathrm{Tyr}^{193}-\mathrm{GIn}^{194}$ ) son preferentemente hidrolizados, y se encuentran en la superficie de la molécula de caseína (Juillard y col., 1995).

\subsubsection{FACTORES DEL PROCESO QUE INFLUYEN EN LA ACTIVIDAD Y ESPECIFICIDAD DE LA CEP}

\section{a) Tiempo de fermentación}

La actividad de proteolítica de la CEP más alta para los lactobacilos, se ha observado durante la fase logarítmica de crecimiento, posteriormente muestra un incremento ligero hasta el fin del tiempo de fermentación (Meijer y col., 1996; Fernández de Palencia y col., 1997; Ul-Haq y col., 2006; Guo y col., 2009; Pan y col., 2010; SadatMekmene y col., 2011).

Algunos autores señalan que la máxima intensidad de la hidrólisis se da en 6 horas de incubación. Tiempos más prolongados de incubación, por ejemplo 24 horas 
pueden incluso disminuir la actividad de la enzima a valores de entre $12 \%$ y $19 \%$ (Fernández de Palencia y col., 1997), mientras otros autores reportan valores de actividad residual tan bajos como $0.1 \%$ (Juillard y col., 1995).

\section{b) Condiciones de incubación pH y temperatura $(T)$}

Las características de una incubación como lo son el $\mathrm{pH}$, y la temperatura no sólo influyen en la tasa de hidrólisis sino también en su especificidad (Fernandez-Espla y col., 2000). De estos dos factores el que mayor efecto tiene sobre la actividad es la temperatura (Gobbetti y col., 1999) sin embargo ambos factores están íntimamente relacionados.

La actividad de algunas CEP es afectada con diferente intensidad por el pH según el sustrato ( $\alpha s_{1} \circ \beta-C N$ ), por ejemplo la reducción del $\mathrm{pH}$ tiene un efecto negativo sobre la actividad de la CEP de Lc. lactis T12 con un mayor impacto sobre $\mathrm{as}_{1}-\mathrm{CN}$ que sobre $\beta-C N$ (Gobbetti y col., 1999).

La adición de $\mathrm{CaCO}_{3}$ a un cultivo de $L$. casei en leche, causó un gran incremento en la degradación de proteína durante la incubación prolongada. El efecto del $\mathrm{CaCO}_{3}$ fue probablemente debido al mantenimiento de la reacción en los cultivos de leche a pH 5.0 o mayor (Brandsaeter y Nelson, 1955).

Se ha mencionado que en periodos prolongados de incubación una enzima puede reducir su actividad, sin embargo esta reducción es más significativa a altas temperaturas, pues mientras que en $24 \mathrm{~h}$ a $30^{\circ} \mathrm{C}$, la actividad residual es de 12 $19 \%$, a $50{ }^{\circ} \mathrm{C}$ pierde toda su actividad durante ese $\mathrm{m}$ ismo periodo (Fernández de Palencia y col., 1997).

Por su parte, en un estudio sobre $L b$. casei, el almacenamiento en frío también tuvo un impacto sobre la hidrólisis, pues reduce la actividad de la enzima (Brandsaeter y Nelson, 1955).

Otra interacción entre el pH y la temperatura, está relacionada con la estabilidad térmica de la enzima, pues la CEP de $L b$. casei es más termoestable a pH entre 5.0 y 5.5, de hecho 5.0 es el $\mathrm{pH}$ al cual mantiene el 50\% de actividad (Brandsaeter y Nelson, 1955). 


\section{c) Otros factores}

La actividad proteolítica de las CEP en presencia de calcio muestra resultados diferentes según la especie y cepa, aunque generalmente se le reconoce a este ion por actuar como estabilizante y activador de las CEP; por ejemplo en el caso de $S$. thermophilus, Lb. casei, y otras especies, los iones calcio en forma de $\mathrm{CaCl}_{2}$ incrementan la actividad enzimática en condiciones experimentales (Kojic y col., 1991; Fernández de Palencia y col., 1997; Fernandez-Espla y col., 2000; SadatMekmene y col., 2011).

Otro factor que actúa sobre la estabilidad es la fuerza iónica, pues con concentraciones de $\mathrm{NaCl}$ por arriba de 4\% disminuye su actividad proteolítica, además la interferencia de la fuerza iónica del medio varía con la fracción de caseína y puede modificar los sitios disponibles para hidrólisis enzimática (Reid y Coolbear, 1998; Gobbetti y col., 1999).

\subsection{Lactobacillus casei}

Lactobacillus casei es una bacteria Gram-positiva, no mótil, no esporulada, catalasa negativa. Sus células son bastones de 0.7-1.1 x 2.0-4.0 $\mu \mathrm{m}$, y tiende a formar cadenas. Es frecuentemente encontrada en alimentos como queso, leche cruda, leche fermentada, vegetales fermentados, salsas crudas, carne, aunque también en forraje fermentado, masa fermentada, el tracto intestinal humano, boca y vagina. Esta bacteria se distingue por su capacidad de crecer en sustratos raramente usados por otras bacterias lácticas (gluconato y malato); son necesarios para su crecimiento riboflavina, ácido fólico, pantotenato de calcio y niacina.

El uso terapéutico como probiótico de $L b$. casei ha sido ampliamente evaluado, pues se ha demostrado que reduce la severidad y duración de la diarrea. Además estimula la respuesta inmune del intestino, alivia los síntomas de la enfermedad de Crohn y posee fuertes propiedades antimicrobianas, pues es capaz de colonizar el intestino de varios mamíferos, y de esta forma puede prevenir la estancia en el intestino de bacterias patógenas compitiendo con éstas por los receptores de glicoesfingolípidos 
(Figueroa-González y col., 2011; Rojas-Ronquillo, 2012).

Una subespecie de esta bacteria es Lb. casei Shirota, y se ha demostrado que previene la diarrea causada por virus o bacterias. Además, tiene un efecto preventivo en la tasa de recurrencia de cáncer superficial de vejiga después de la cirugía (Figueroa-González y col., 2011).

En la actualidad, Lb. casei se emplea en alimentos o en preparaciones especiales como probiótico. Desde el punto de vista tecnológico, Lb. casei está dentro de las especies de BAL más comúnmente usadas por producir enzimas proteolíticas. Por ello han sido varios los investigadores que estudian la proteólisis efectuada por $L b$. casei. Se han estudiado las cepas Lb. casei 2607 y 15286, Lb. casei 25, Lb. casei HN14, Lb. casei IFPL 731 y Lb. casei YIT9029 entre otras (Brandsaeter y Nelson, 1955; Kojic y col., 1991; Fernández de Palencia y col., 1997; Ramachandran y Shah, 2008; Gonzalez-Gonzalez y col., 2011).

Ul-Haq y Mukhtar (2006), estudiaron la optimización de las condiciones de cultivo de diferentes especies de BAL para la producción de proteasas. De ellas $L b$. paracasei fue identificada como la más proteolítica encontrando el óptimo de producción de enzima a $35^{\circ} \mathrm{C}$ pH 6.0. Ramachandran y Shah (2008) e studiaron el crecimiento, perfiles proteolíticos y potencial inhibitorio de ACE de ciertas cepas. Entre ellas $L b$. casei 2607 y 15286 incubadas en leche, donde ésta fue una de las de mayor potencial inhibitorio de ACE (después de Bb. longum y Lb. delbrueckii subsp. bulgaricus).

Otros investigadores han estudiado la bioactividad de los hidrolizados de Lb. casei: con respecto a la actividad inhibidora de la ACE. Ong y col. (2007), estudiaron Lb. casei LAFTI, concluyendo que además de ser una bacteria probiótica y formar parte de la flora de los productos madurados, tiene potencial como liberador de péptidos bioactivos. Pihlanto y col. (2010), estudiaron diferentes cepas, y dentro de las que presentaron una máxima actividad inhibitoria de la enzima convertidora de angiotensina se encontró una cepa de $L b$. casei, que presentó un máximo de actividad a las 24 horas de la incubación.

Rojas-Ronquillo y col. (2012), estudiaron la actividad antitrombótica de un hidrolizado 
de caseína con $L b$. casei Shirota, encontrando una máxima actividad a las 27 horas. De los siete péptidos purificados, uno mostró la máxima actividad aún después de una simulación gástrica. Este péptido (YQEPVLGPVRGPFIIV) provino de $\beta-C N$ y había sido reportado previamente como citomodulador y antihipertensivo. 


\section{JUSTIFICACIÓN}

Los péptidos bioactivos son reconocidos por promover beneficios a la salud en el organismo humano. La producción de estos péptidos durante la fermentación de la leche depende de múltiples factores. Dentro de estos factores la temperatura, el tiempo de fermentación y el $\mathrm{pH}$, tienen un efecto directo sobre la actividad proteolítica. Este efecto se ve relacionado tanto en la intensidad como en la especificidad de corte de algunas secuencias peptídicas.

Lactobacillus casei Shirota, es una BAL probiótica de importancia industrial. A pesar de que se ha demostrado que este microorganismo produce péptidos bioactivos durante la fermentación, existen pocos estudios en relación a la síntesis de este tipo de compuestos por esta cepa, especialmente en la producción de péptidos con carácter antitrombótico y fijador de minerales.

Por lo anterior es necesario profundizar en la relación existente entre las condiciones del proceso fermentativo y la actividad antitrombótica, acarreadora de calcio y acarreadora de hierro de la leche fermentada por Lactobacillus casei Shirota. 


\section{OBJEtivos}

\subsection{Objetivo General}

Determinar las condiciones óptimas de fermentación mediante la inoculación de leche con Lactobacillus casei Shirota para obtener la máxima bioactividad de péptidos acarreadores de minerales y antitrombóticos.

\subsection{OBjetivos PARTICULARES}

a) Obtener péptidos bajo diferentes condiciones de fermentación establecidas mediante un diseño experimental factorial.

b) Identificar las condiciones óptimas de producción de los péptidos bioactivos.

\section{HIPÓTESIS}

Se sabe que las proteínas de la leche liberan péptidos con múltiples actividades debido a la acción del sistema proteolítico de las bacterias ácido lácticas, y que esta liberación depende de las condiciones a las cuales se lleva a cabo el proceso fermentativo. Si establecemos las condiciones de temperatura, $\mathrm{pH}$ y tiempo de fermentación idóneas, podremos favorecer la producción de péptidos bioactivos en leche fermentada. 


\section{DisEÑO DE ESTUDIO}

Se aplicó un diseño factorial donde se consideró como unidad experimental $1 \mathrm{~L}$ de leche descremada Svelty ${ }^{\circledR}$ (estandarizada a $10 \%$ de sólidos y pasteurizada a $115{ }^{\circ} \mathrm{C}$ por 5 minutos) inoculada con $L b$. casei Shirota en un fermentador New Brunswick $\circledast$ BioFlow II. Los factores en este diseño fueron temperatura (37, 39.5 y $\left.42^{\circ} \mathrm{C}\right), \mathrm{pH}(6.0$, 6.25 y 6.5) y tiempo de fermentación (12 y 20 h). Los niveles de los factores temperatura y $\mathrm{pH}$ se establecieron con base en él óptimo de crecimiento de $L b$. casei Shirota ( $\left.\mathrm{pH} 6.5,3^{\circ} \mathrm{C}\right)$ y el óptimo de actividad de su proteinasa de pared celular ( $\mathrm{pH}$ $6.0,42^{\circ} \mathrm{C}$ ). De la combinación de factores se obtuvieron 18 tratamientos que se realizaron por duplicado, de modo que el número de unidades experimentales $(\mathrm{N})$ fue 36.

Las unidades experimentales fueron sometidas a fermentación, y es en esta etapa en la que se aplicaron los tratamientos del diseño. Posteriormente se estudiaron las actividades: fijadora de hierro, fijadora de calcio y antitrombótica. 


\section{Metodología}

\subsection{MICROORGANISMO}

Se activó Lactobacillus casei Shirota, proveniente de un cultivo congelado, en $10 \mathrm{~mL}$ de medio Litmus Milk y se incubó a $37^{\circ} \mathrm{C}$ por $48 \mathrm{~h}$. Posteriormente se transfirieron 3 asadas a $30 \mathrm{~mL}$ de caldo MRS y se incubó a $37^{\circ} \mathrm{C}$ por 24 h. Éste último se empleó como inóculo para las fermentaciones en el estudio.

\subsection{FERMENTACIÓN DE LA LECHE}

Se inoculó en al $1 \%$ de cultivo inicial $1 \mathrm{~L}$ de leche descremada Svelty ${ }^{\circledR}$ reconstituida a $10 \%$ de sólidos, pasteurizada a 115 C/5 min, con un cultivo de $L b$. casei Shirota crecido en caldo MRS (densidad óptica de 0.327 unidades de absorbancia). Los tratamientos realizados se indican en la tabla 1. El pH se controló con la adición de $\mathrm{NaOH} 2 \mathrm{~N}$ y ácido acético $2 \mathrm{~N}$ según se requirió. Se efectuó un experimento adicional permitiendo el descenso del $\mathrm{pH}$, con la finalidad de identificar la mitad y el término de la fase de crecimiento exponencial, etapa que algunos autores señalan como la de mayor producción de péptidos.

Se colectaron $100 \mathrm{~mL}$ de leche fermentada de cada unidad experimental para posteriormente determinar las bioactividades estudiadas.

Para establecer numéricamente la mitad y el término de la fase exponencial de crecimiento y considerar dichos valores dentro del diseño experimental, se llevaron a cabo cuatro fermentaciones de prueba. 
Tabla 1. Combinación de factores para el diseño factorial

\begin{tabular}{|c|c|c|c|c|c|c|c|}
\hline & \multicolumn{6}{|c|}{ Tiempo (h) } \\
\hline & & \multicolumn{3}{|c|}{12} & \multicolumn{3}{|c|}{20} \\
\hline & & \multicolumn{3}{|c|}{ Temperatura $\left({ }^{\circ} \mathrm{C}\right)$} & \multicolumn{3}{|c|}{ Temperatura $\left({ }^{\circ} \mathrm{C}\right)$} \\
\hline & & 37.0 & 39.5 & 42.0 & 37.0 & 39.5 & 42.0 \\
\hline \multirow[t]{3}{*}{$\mathrm{pH}$} & 6.00 & 1 & 2 & 3 & 10 & 11 & 12 \\
\hline & 6.25 & 4 & 5 & 6 & 13 & 14 & 15 \\
\hline & 6.50 & 7 & 8 & 9 & 16 & 17 & 18 \\
\hline
\end{tabular}

\subsection{Recuento en PLACA}

Se tomaron muestras de leche fermentada de las cuatro fermentaciones de prueba a diferentes tiempos para determinar las cinéticas de crecimiento. Se efectuaron diluciones de la muestra desde $10^{-3}$ hasta $10^{-9}$ en agua peptonada (conteniendo $0.85 \%$ de $\mathrm{NaCl}$ y $0.1 \%$ peptona de caseína) y se transfirieron $5 \mu \mathrm{L}$ de cada dilución a una placa con agar MRS por duplicado. Se incubaron a $37^{\circ} \mathrm{C}$ por $24 \mathrm{~h}$ y se efectuó el recuento en aquellas diluciones que presentaron de 25 a 100 colonias (FigueroaGonzález, 2010).

\subsection{DETERMINACIÓN DE ACTIVIDAD FIJADORA DE CALCIO}

Se realizó de acuerdo con el método reportado por Figueroa-Hernández y col. (2012) con algunas modificaciones. Se adicionó $1 \mathrm{~mL}$ de ácido tricloroacético al $80 \%$ a $6 \mathrm{~mL}$ de la leche fermentada, colectada de cada unidad experimental. Se centrifugó a 10,000 rpm por 30 minutos. Se tomó el sobrenadante y se ajustó el pH a 8.0 con $\mathrm{NaOH} 2 \mathrm{~N}$. Se determinó el contenido de proteínas por la técnica de Lowry y col. (1951). Posteriormente se mezclaron $2 \mathrm{~mL}$ de $\mathrm{CaCl}_{2} 1 \mathrm{mM}$ con un $1 \mathrm{~mL}$ de una dilución 1:100 de la muestra (en solución amortiguadora de fosfatos $20 \mathrm{mM} \mathrm{pH} \mathrm{8.0).}$ Se tomó una alícuota de $50 \mu \mathrm{L}$ de la mezcla anterior y $1 \mathrm{~mL}$ de arsenazo III (Genzyme, Co., E. U. A.) y se incubó a una temperatura entre 18 a $26^{\circ} \mathrm{C}$ durante 30 
segundos. Se midió la absorbancia a $650 \mathrm{~nm}$ (espectrofotómetro Shimadzu UV-180, Japón) contra un blanco de agua desionizada. A este valor se le nombró calcio inicial. Adicionalmente se incubó la mezcla formada por la muestra diluida 1:100 y el $\mathrm{CaCl}_{2}$ por 30 minutos con agitación constante a temperatura ambiente. Se tomó una alícuota de $50 \mu \mathrm{L}$ de la mezcla previamente incubada y $1 \mathrm{~mL}$ de arsenazo III y se incubó a una temperatura entre 18 y $26{ }^{\circ} \mathrm{C}$ durante 30 segundos y se midió la absorbancia a $650 \mathrm{~nm}$ contra un blanco de agua desionizada. Este valor se nombró calcio final. El calcio fijado se calculó con la siguiente ecuación:

$\mathrm{mmolCa}{ }^{2+} / \mathrm{mg}$ prot. $=\left[\mathrm{Ca}^{2+}{ }_{\text {inicial }}\right]-\left[\mathrm{Ca}^{2+}{ }_{\text {final }}\right] /[$ prot $]$

Donde:

$\left[\mathrm{Ca}^{2+}{ }_{\text {final }}\right]$ es la concentración de calcio final.

$\left[\mathrm{Ca}^{2+}{ }_{\text {inicial }}\right]$ es la concentración de calcio inicial.

[prot] es la concentración de proteína en la reacción determinada por la técnica de Lowry.

Todos los materiales utilizados en esta metodología se lavaron con $\mathrm{HCl} 1 \mathrm{~N}$ durante la noche anterior y se enjuagaron posteriormente con agua desionizada para evitar trazas de calcio que pudieran interferir con las determinaciones.

\subsection{OBTENCIÓN DEL EXTRACTO LIBRE DE CÉLULAS (ELC)}

Se ajustó el pH de la leche fermentada a 9.2 para solubilizar caseínas. Se centrifugó a 10,000 rpm por 30 minutos y se recolectó el sobrenadante. Éste se empleó en la determinación de actividad fijadora de hierro y antitrombótica.

\subsection{DETERMINACIÓN DE ACTIVIDAD FIJADORA DE HIERRO}

Se determinó el contenido de proteínas del ELC por la técnica de Lowry (1951). Se diluyó la muestra con agua desionizada para estandarizar el contenido de proteína a $0.2 \mathrm{mg} / \mathrm{mL}$. Se tomó una alícuota de $3.7 \mathrm{~mL}$ de la dilución anterior y mezcló con 0.1 
$\mathrm{mL}$ de $\mathrm{FeCl}_{2} 2 \mathrm{mM}$ y se incubó durante 30 minutos a temperatura ambiente. Se mezcló con $0.2 \mathrm{~mL}$ de ferrozina $5 \mathrm{mM}$, se incubó la mezcla anterior durante 10 minutos a temperatura ambiente y se midió la absorbancia a $562 \mathrm{~nm}$. Este valor corresponde al hierro final.

Adicionalmente se repitió el análisis con un testigo, sustituyendo la muestra por agua desionizada. Este valor corresponde al hierro inicial. El hierro fijado se calculó mediante la siguiente ecuación:

$\mathrm{mg} \mathrm{Fe}{ }^{2+} / \mathrm{mg}$ prot. $=\left[\mathrm{Fe}^{2+}{ }_{\text {inicial }}\right]-\left[\mathrm{Fe}^{2+}{ }_{\text {final }}\right] /[$ prot $]$

Donde:

$\left[\mathrm{Fe}^{2+}{ }_{\text {final }}\right]$ es la concentración de hierro en la reacción al utilizar muestra.

$\left[\mathrm{Fe}^{2+}{ }_{\text {inicial }}\right]$ es la concentración de hierro en la reacción al utilizar agua desionizada en vez de la muestra.

[prot] es la concentración de proteína en la reacción.

\subsection{DETERMINACIÓN DE ACTIVIDAD ANTITROMBÓTICA}

La actividad antitrombótica se determinó de acuerdo al método de Zhang y col. (2008). Se preparó una dilución 1:3 del ELC en solución amortiguadora de Tris - HCl $0.05 \mathrm{M}$ a pH 7.2, conteniendo $\mathrm{NaCl}$ en una concentración de $0.12 \mathrm{mM}$. Se colocaron en una placa de ELISA $40 \mu \mathrm{L}$ de la dilución anterior junto con $140 \mu \mathrm{L}$ de fibrinógeno humano (Sigma-Aldrich, E. U. A.) al $0.1 \%$. Se incubó a $37^{\circ} \mathrm{C}$ por 10 minutos y se leyó la absorbancia en el lector de microplacas (Beckman ELx800, E. U. A.) a 405 $\mathrm{nm}$. Posteriormente se adicionaron $10 \mu \mathrm{L}$ de trombina $12 \mathrm{U} / \mathrm{mL}$ (Sigma-Aldrich, E. U. A.). Se incubó a $3^{\circ} \mathrm{C}$ por 10 minutos y se midió la absorbancia en el lector de microplacas a $405 \mathrm{~nm}$. Adicionalmente se preparó un control negativo sustituyendo la muestra y la enzima por solución amortiguadora, y un control positivo sustituyendo la muestra por solución amortiguadora. 
Se calculó la tasa de inhibición de formación del coágulo "Y" mediante la siguiente ecuación:

$$
Y=[(A-B) /(C-D)] /(A-B) * 100 \%
$$

Donde:

A es la absorbancia del control negativo.

B es la absorbancia del control positivo.

C es la absorbancia del sistema conteniendo la muestra problema y el fibrinógeno después de incubar.

D es la absorbancia del sistema conteniendo la muestra problema, el fibrinógeno y la trombina después de incubar.

Se determinó la actividad antitrombótica específica (AE) mediante la siguiente ecuación:

\section{$A E=Y /$ prot}

Donde:

Y es la tasa de inhibición de formación del coágulo expresada en \%.

prot es el contenido en miligramos de proteínas presentes en la mezcla de reacción.

\subsection{DETERMinACIÓN DE PROTEÍNAS}

La cuantificación de proteínas se realizó mediante la técnica reportada por Lowry y col. (1951). Se mezclaron 50 volúmenes de $\mathrm{Na}_{2} \mathrm{CO}_{3}$ al $2 \%$ en $\mathrm{NaOH} 0.1 \mathrm{~N}$ con un volumen de $\mathrm{CuSO}_{4}$ al $1 \%$ en $\mathrm{H}_{2} \mathrm{O}$ y con un volumen de tartrato de $\mathrm{Na}$ y $\mathrm{K}$ al $2 \%$ en $\mathrm{H}_{2} \mathrm{O}$. A cada mililitro de la muestra se le adicionaron $5 \mathrm{~mL}$ de la solución anterior. Se dejó reposar 10 minutos en la oscuridad y se agregaron $0.5 \mathrm{~mL}$ de reactivo de FolinCiocalteu 1:1 en agua. Se dejó reposar 30 minutos en la oscuridad y se midió la 
absorbancia a una longitud de onda de $590 \mathrm{~nm}$ en el espectrofotómetro (Shimadzu UV-180, Japón).

Adicionalmente se preparó una curva patrón a partir de una solución de $500 \mu \mathrm{g} / \mathrm{mL}$ de seroalbúmina (Sigma-Aldrich, E. U. A.) a diferentes concentraciones en un intervalo de 0 a $500 \mu \mathrm{g} / \mathrm{mL}$.

\subsection{ANÁLISIS ESTADÍSTICO}

Se aplicó el análisis de varianza de una vía $(\alpha=0.05)$, y una prueba Tukey $(\alpha=0.05)$ como prueba de comparación de medias. 


\section{RESULTADOS Y DISCUSIÓN}

\subsection{DETERMINACIÓN DE CURVAS DE CRECIMIENTO DE Lactobacillus casei SHIROTA}

De acuerdo con varios autores, las máximas actividades de los hidrolizados de leche se obtienen entre la mitad y el término de la fase exponencial de crecimiento (Ramachandran y Shah, 2008; Pan y Guo, 2010; Gonzalez-Gonzalez y col., 2011). Rojas-Ronquillo (2012) reporta que el término de la fase exponencial de Lb. casei Shirota se presentó entre 15 y 20 horas, al emplear un medio de caseína a $3^{\circ} \mathrm{C}$.

En la figura 1 se pueden observar las cinéticas de crecimiento de $L b$. casei Shirota obtenidas bajo diferentes condiciones de fermentación. Como puede apreciarse, en todos los casos, el microorganismo comienza a reproducirse desde el inicio de la fermentación, es decir, no se presenta la fase de crecimiento lag, esto puede deberse a que las células presentes en el inóculo empleado se encontraban en fase exponencial. La fase exponencial de crecimiento concluyó a diferentes tiempos según las combinaciones de $\mathrm{pH}$ y temperatura estudiadas: para la combinación de $\mathrm{pH} 6.5 / 42{ }^{\circ} \mathrm{C}$ se dio a las 12 horas, para $\mathrm{pH} 6.5 / 37^{\circ} \mathrm{C}$ y pH 6.5/39 ${ }^{\circ} \mathrm{C}$ a las 16 horas, y para $\mathrm{pH} 6.0 / 42{ }^{\circ} \mathrm{C}$ fue 20 horas.

Asimismo, en la figura 1 se presenta la cinética de un experimento adicional en el cual se fermentó la leche a $37^{\circ} \mathrm{C}$, en este caso perm itiendo el descenso natural del $\mathrm{pH}$ a partir de un valor inicial de 6.5. Esta fermentación a pH descendente se procesó a fin de comparar su cinética de crecimiento con las correspondientes a las 4 fermentaciones de prueba. Para esta fermentación a $37{ }^{\circ} \mathrm{C}$ sin control de pH el término de la fase exponencial se presentó a las 20 horas. Con esta fermentación se comprobó que el mantener el pH constante no cambia el tiempo de fermentación del microorganismo, en comparación con una fermentación sin control de pH (para el sistema y condiciones estudiados).

Con la finalidad de estandarizar los tiempos de fermentación a manejarse dentro del diseño experimental, se seleccionaron únicamente dos niveles de tiempo, correspondientes a 12 y 20 horas, debido a que estos dos valores se aproximan a la 
mitad y término de la fase exponencial de crecimiento respectivamente.

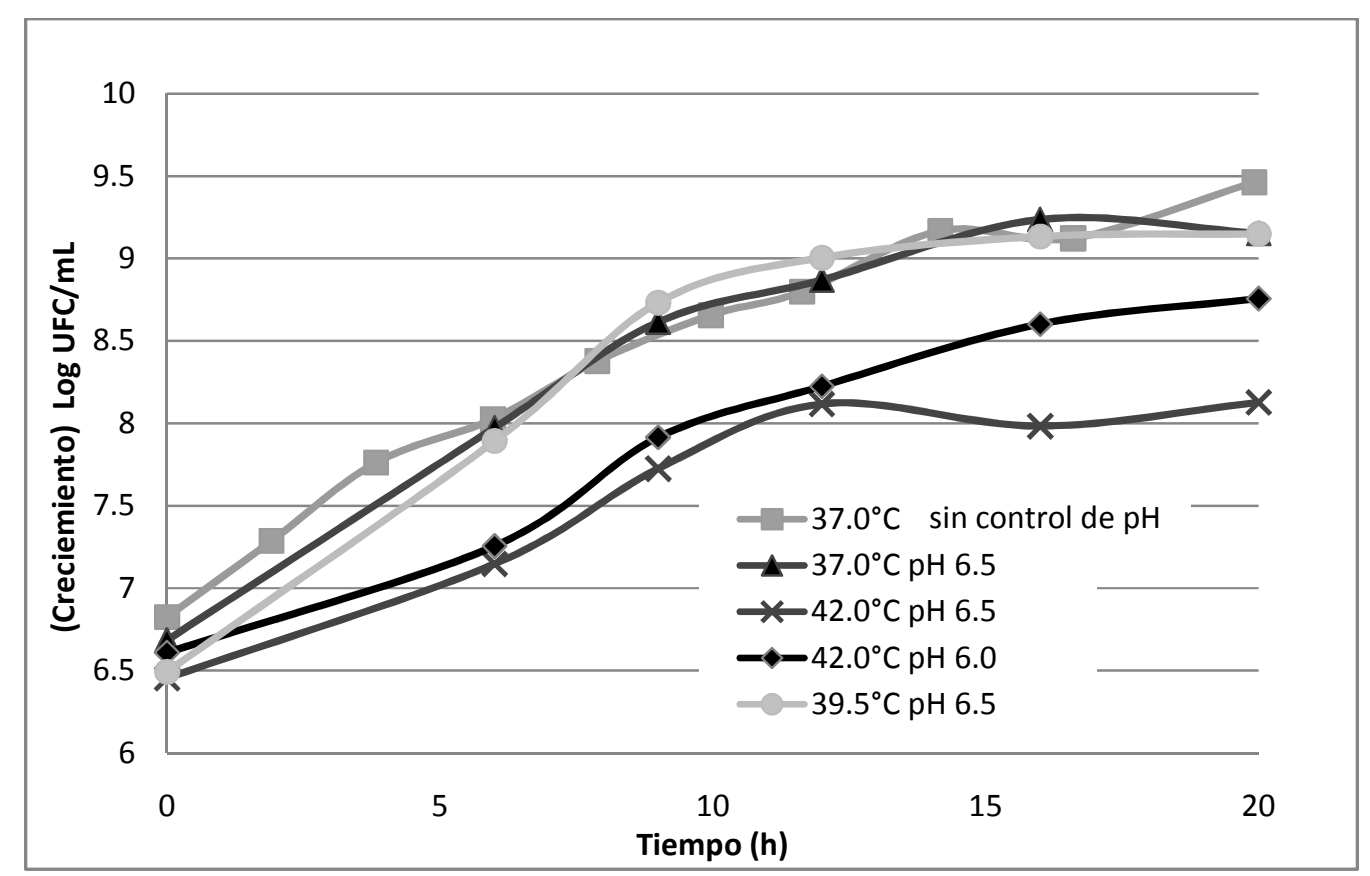

Fig. 1. Cinéticas de crecimiento de Lactobacillus casei Shirota bajo diferentes condiciones de temperatura y $\mathrm{pH}$.

\subsection{ACTIVIDAD FIJADORA DE HIERRO}

Se determinó la actividad fijadora de hierro de los 18 tratamientos aplicados por duplicado. Los resultados de actividad se presentan en la figura 2. A fin de conocer si las condiciones de proceso tienen influencia sobre la actividad, se realizó un análisis de varianza $(\alpha=0.05)$. Los resultados del análisis mostraron que al aplicar los tratamientos 2, 3, 6 y 18 se obtuvo la mayor actividad, estos corresponden a la combinación de tratamientos $\mathrm{pH} 6.0 / 39.5{ }^{\circ} \mathrm{C} / 12 \mathrm{~h}, \mathrm{pH} 6.0 / 42{ }^{\circ} \mathrm{C} / 12$ h, pH 6.25/42 ${ }^{\circ} \mathrm{C} / 12 \mathrm{~h}$ y $\mathrm{pH} 6.5 / 42{ }^{\circ} \mathrm{C} / 20 \mathrm{~h}$, respectivamente, y los valores de actividad fijadora de hierro fueron $4.62 \cdot 10^{-4}, 3.10 \cdot 10^{-4}, 2.35 \cdot 10^{-4}$ y $2.40 \cdot 10^{-4} \mathrm{mmol}$ de $\mathrm{Fe}^{2+}$ fijado por $\mathrm{mg}$ de proteína, respectivamente. De estos cuatro tratamientos tres comparten el mismo tiempo de fermentación (12 h) y tres la misma temperatura de fermentación $\left(42^{\circ} \mathrm{C}\right)$. Con base en lo anterior se puede decir que una temperatura de $42{ }^{\circ} \mathrm{C}$ y un tiempo de 
fermentación de 12 horas favorecieron la actividad fijadora de hierro del ELC de leche fermentada. Esta temperatura no favoreció el crecimiento del microorganismo, como se aprecia en la figura 1, en cambio pudo haber favoreció la actividad de la proteinasa de pared celular de Lb. casei Shitora de acuerdo con Brandsaeter y Nelson (1955).

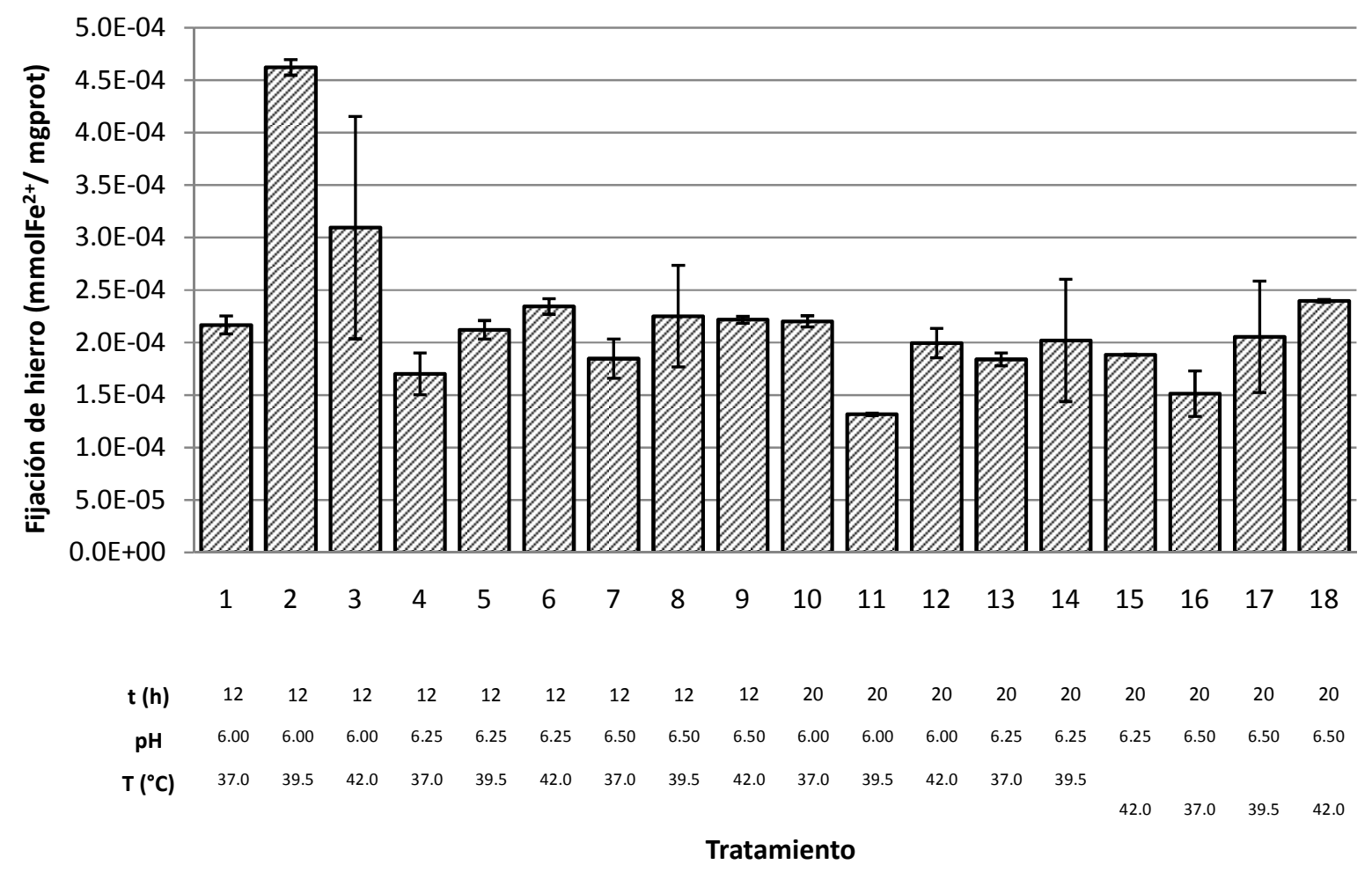

Fig. 2. Actividad fijadora de hierro para las muestras de los diferentes tratamientos

En la figura 3 se presenta una serie de gráficas para analizar cada uno de los factores estudiados $(\mathrm{pH}$, temperatura y tiempo de fermentación) de manera independiente. Para afirmar si existe o no una diferencia entre aplicar un nivel u otro de cada variable en estudio ( $\mathrm{T}, \mathrm{pH}$ y tiempo de fermentación), se recurrió a una análisis de varianza $(\alpha=0.05)$ en cada caso. Cabe señalar que la discusión se basa en los resultados y el análisis es estadístico.

Al mantener fijo el tiempo de fermentación en 12 horas (Fig. 3-A), a pH 6.25 se observó la mayor actividad a $42^{\circ} \mathrm{C}$; mientras que a valores de $\mathrm{pH}$ de 6.0 y 6.5 , 
estadísticamente no hubo diferencia entre aplicar cualquiera de las tres temperaturas $(\alpha=0.05)$.

Al mantener el tiempo fijo en 20 horas (Fig. 3-B), a pH 6.0 la actividad disminuyó al aumentar la temperatura de $37^{\circ} \mathrm{C}$ a $39.5^{\circ} \mathrm{C}$ y al au mentar la temperatura de $39.5^{\circ} \mathrm{C}$ a $42^{\circ} \mathrm{C}$ la actividad también aumentó. Estadísticame nte $(\alpha=0.05)$ no hubo un efecto de la temperatura a $\mathrm{pH} 6.25 \mathrm{ni}$ a $\mathrm{pH} 6.5$.
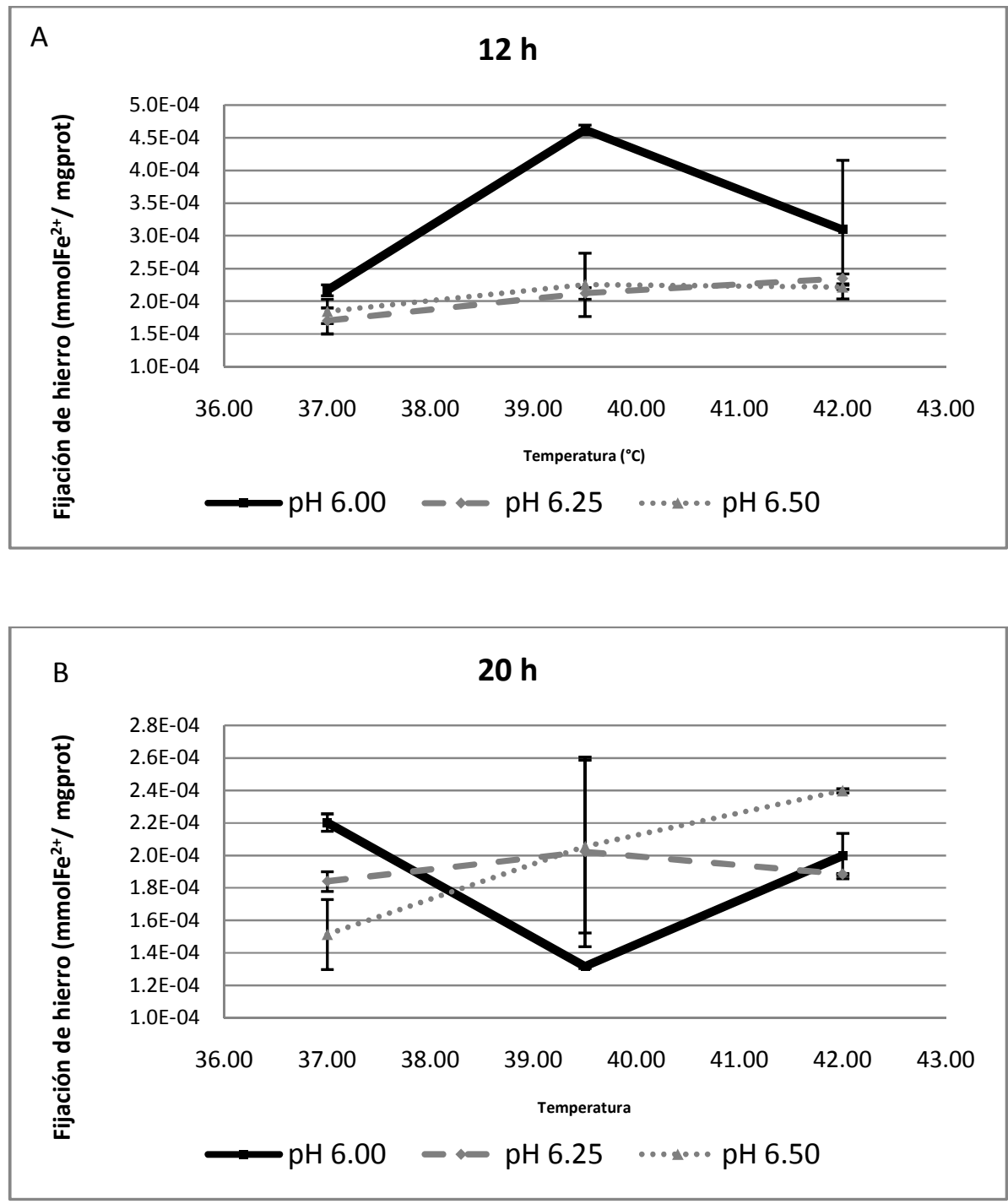

Fig. 3. Actividad fijadora de hierro en función de la temperatura a (A) 12 horas y (B) 20 horas. 

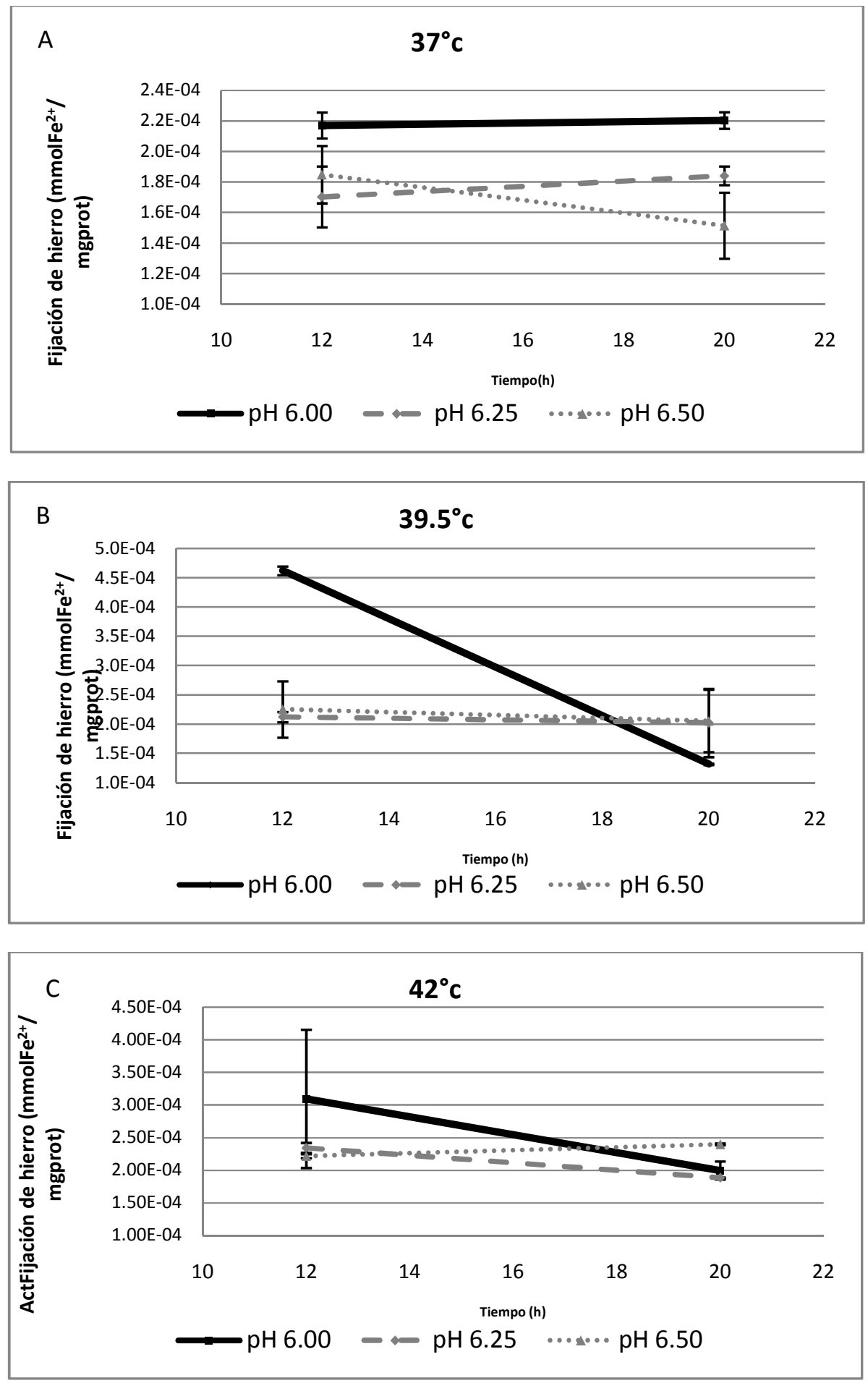

Fig. 4. Actividad fijadora de hierro en función del tiempo de fermentación a (A) $37^{\circ} \mathrm{C}$, (B) $39.5^{\circ} \mathrm{C}$ y (C) $42 \stackrel{\circ}{\circ}$. 

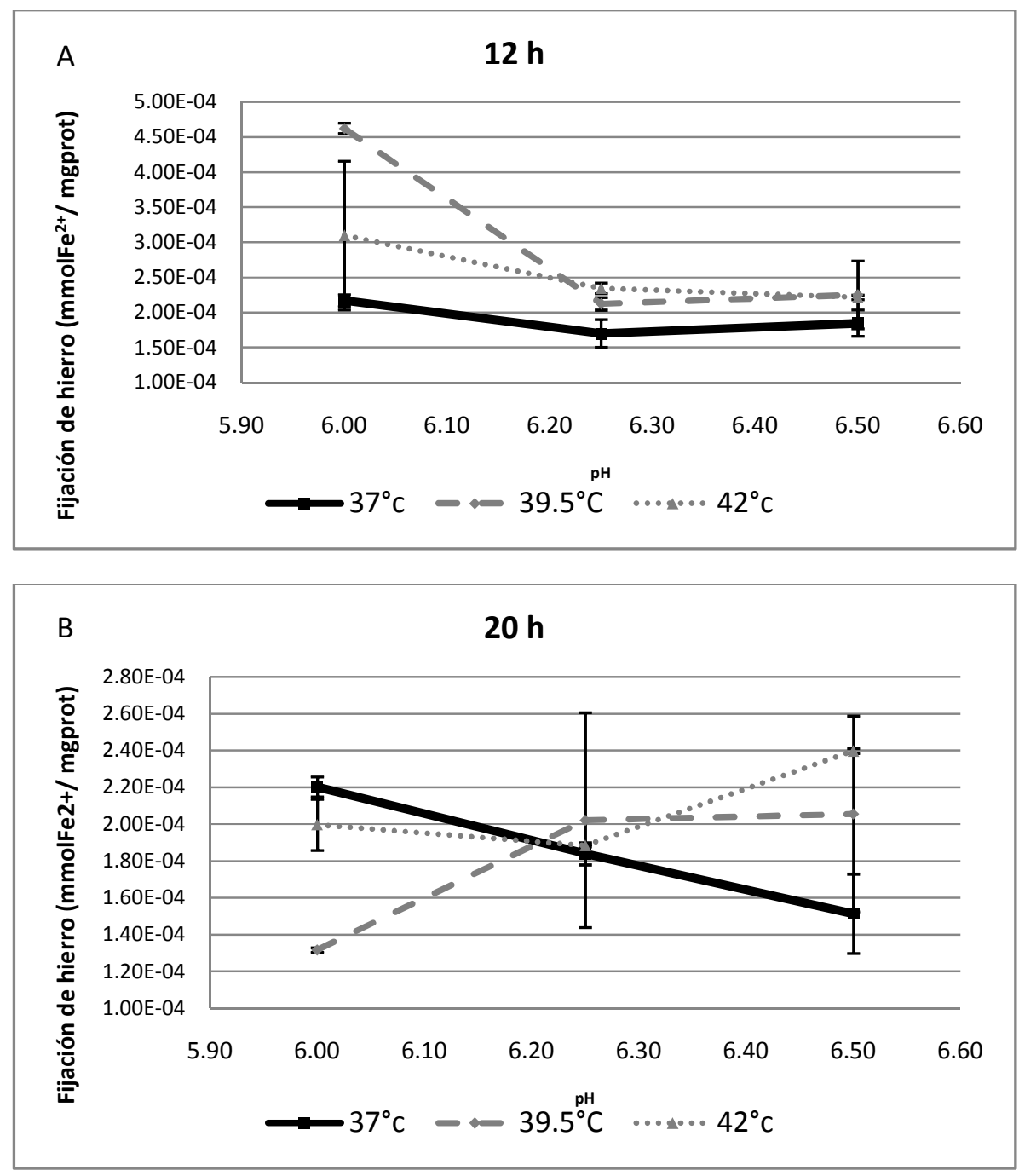

Fig. 5. Actividad fijadora de hierro en función del pH a (A) 12 horas y (B) 20 horas.

Al mantener la temperatura fija en $37^{\circ} \mathrm{C}$ (Fig. 4-A), estadísticamente ( $\left.\alpha=0.05\right)$ no hubo efecto del tiempo de fermentación a ninguno de los $\mathrm{pH}$ estudiados. Al mantener la temperatura fija en $39.5{ }^{\circ} \mathrm{C}$ (Fig. 4-B), a pH 6.0 la actividad disminuyó significativamente, de 12 a 20 horas; no hubo efecto significativo $(\alpha=0.05)$ del tiempo de fermentación sobre la actividad a pH 6.25 y 6.5. Al mantener la temperatura fija en $42{ }^{\circ} \mathrm{C}$ (Fig. 4-C), estadísticamente $(\alpha=0.05$ ) no hubo efecto del tiempo a pH 6.0, sin embargo a pH 6.25 la actividad disminuyó de 12 a 20 horas de fermentación; a pH 6.5 ocurrió lo contrario, pues la actividad aumentó de 12 a 20 horas. 
Al mantener fijo el tiempo en 12 horas (Fig. 5-A), a $39.5^{\circ} \mathrm{C}$ la actividad fue mayor a $\mathrm{pH} 6.0$ y posteriormente disminuyó sin haber una diferencia significativa $(\alpha=0.05)$ entre actividades a pH 6.25 y 6.5. En el caso de $37^{\circ} \mathrm{C}$ y $42^{\circ} \mathrm{C}$ no hubo efecto del pH sobre la actividad debido al traslape de los intervalos de confianza de dichos valores de actividad $(\alpha=0.05)$.

A I mantener fijo el tiempo en 20 horas (Fig. 5-B), a $37^{\circ} \mathrm{C}$ la actividad disminuyó al aumentar el $\mathrm{pH}$, mientras que a $39.5^{\circ} \mathrm{C}$ no hubo efec to del $\mathrm{pH}$ sobre la actividad y a $42^{\circ} \mathrm{C}$ la actividad aumentó cuando el pH fue de 6.5.

Con base en lo anterior se concluye que únicamente la combinación de las tres variables estudiadas, temperatura, tiempo y $\mathrm{pH}$ tienen un efecto favorable sobre la actividad fijadora de hierro en el caso de los tratamientos 2, 3, 6 y 18. Por otra parte, no se aprecia con claridad la influencia de cada uno de los factores estudiados, de manera independiente.

Existe muy poca información reportada sobre la fijación de hierro por parte de péptidos de leche. Farvin y col. (2010) reportaron que las fracciones peptídicas del yogurt tenían hasta un $7.7 \%$ de actividad fijadora de hierro. Figueroa-Hernández y col. (2012) han reportado que los hidrolizados de leche obtenidos por fermentación con Lactococcus lactis subsp. cremoris NCFB 712, mostró una fijación de hierro con valores entre 30 y $60 \%$. Con la finalidad de comparar los resultados del presente estudio con datos previamente reportados, en la figura 6 se presentan los datos de actividad expresados en porcentaje de fijación de hierro. Los valores van de 48.8 a $88.7 \%$ de hierro fijado, y son mayores a los reportados por los investigadores antes citados. Cabe señalar que las especies bacterianas estudiadas en dichos trabajos son diferentes a $L b$. casei Shirota, lo cual puede ser indicativo de que la diferencia entre la capacidad de fijación de hierro también puede ser dependiente del tipo de microorganismo y de la especificidad de su sistema proteolítico. 


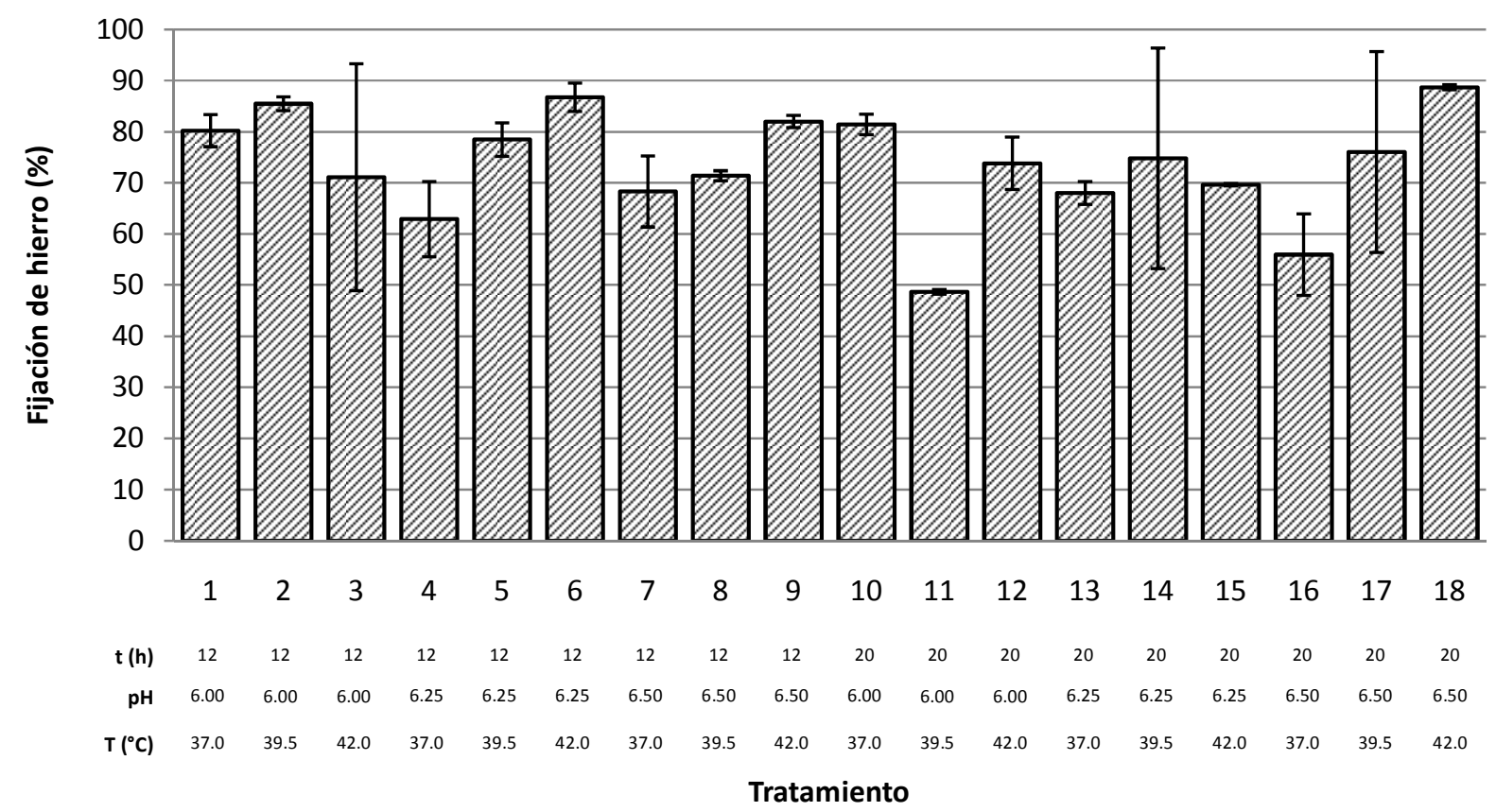

Fig. 6. Actividad fijadora de hierro para las muestras de los diferentes tratamientos

\subsection{ACTIVIDAD ANTITROMBÓTICA}

Se determinó la actividad antitrombótica de los 18 tratamientos aplicados por duplicado. Los resultados del porcentaje de inhibición del coágulo se presentan en la figura 7.

Se realizó un análisis de varianza $(\alpha=0.05)$ para conocer si el tratamiento aplicado durante la fermentación tuvo una influencia sobre el porcentaje de inhibición del coágulo. Para facilitar este análisis se descartaron seis tratamientos que presentaron las mayores desviaciones estándar en sus actividades (tratamientos 5, 8, 10, 12,15 y 17). El resultado del análisis de varianza indicó que sí existe una influencia del tratamiento y mediante una prueba Tukey $(\alpha=0.05)$ se encontró que siete tratamientos tienen la mayor actividad, sin haber una diferencia significativa entre sus porcentajes de inhibición. Estos tratamientos son el 2, 4, 7, 9, 11, 13 y 16, cuyas 
actividades se estiman entre el 53.5 y el $79.1 \%$, no habiendo una diferencia estadística $(\alpha=0.05)$ entre ellas.

Por su parte las muestras de los tratamientos 1 (pH 6.0/37 $\mathrm{C} / 12$ h) y $6(\mathrm{pH} \mathrm{6.25/42}$ ¿C/12 h) no presentaron inhibición.

Rojas-Ronquillo y col. (2012) estudiaron la actividad antitrombótica de un hidrolizado de caseína con $L b$. casei Shirota, a $37^{\circ} \mathrm{C}$ durante 42 horas de fermentación. Encontraron que a las 20 horas la actividad antitrombótica fue de alrededor del $50 \%$. En el presente estudio se encontró que los mayores porcentajes de inhibición encontrados a $3^{\circ} \mathrm{C}$ y a 20 horas corresponden a los tratamientos 13 y 16 con actividades de 58.2 y $53.5 \%$ de inhibición respectivamente. Estos valores fueron mayores a los reportados por Rojas-Ronquillo y col. La importancia de este comparativo se centra en el hecho de que en el presente estudió se empleó leche como medio de fermentación mientras que Rojas-Ronquillo y col. (2012) utilizaron únicamente caseína, lo cual facilita la purificación del péptido, debido a que se tienen pocos subproductos de la caseína en comparación con todos los subproductos de la leche. Esto quiere decir que la variedad de proteínas y otros componentes de la leche pudieron favorecer la producción de péptidos antitrombóticos, afirmación que necesitaría ser validada con estudios posteriores. Por otra parte, reportan que el mayor porcentaje de inhibición del coágulo se encontró a las 27 horas de fermentación con un valor de $80.7 \%$ de inhibición.

Es importante indicar que en el cálculo del porcentaje de inhibición del coágulo (Fig.7), no se tomó en consideración el contenido de proteínas para poder comparar con los resultados obtenidos por Rojas-Ronquillo y col. (2012). Es importante señalar dicha omisión, debido a que el contenido de péptidos de las muestras depende el contenido de proteínas. Es por ello que se calculó la actividad específica, definida en este caso como el porcentaje de inhibición por cada miligramo de proteína en la reacción (Fig. 8). 


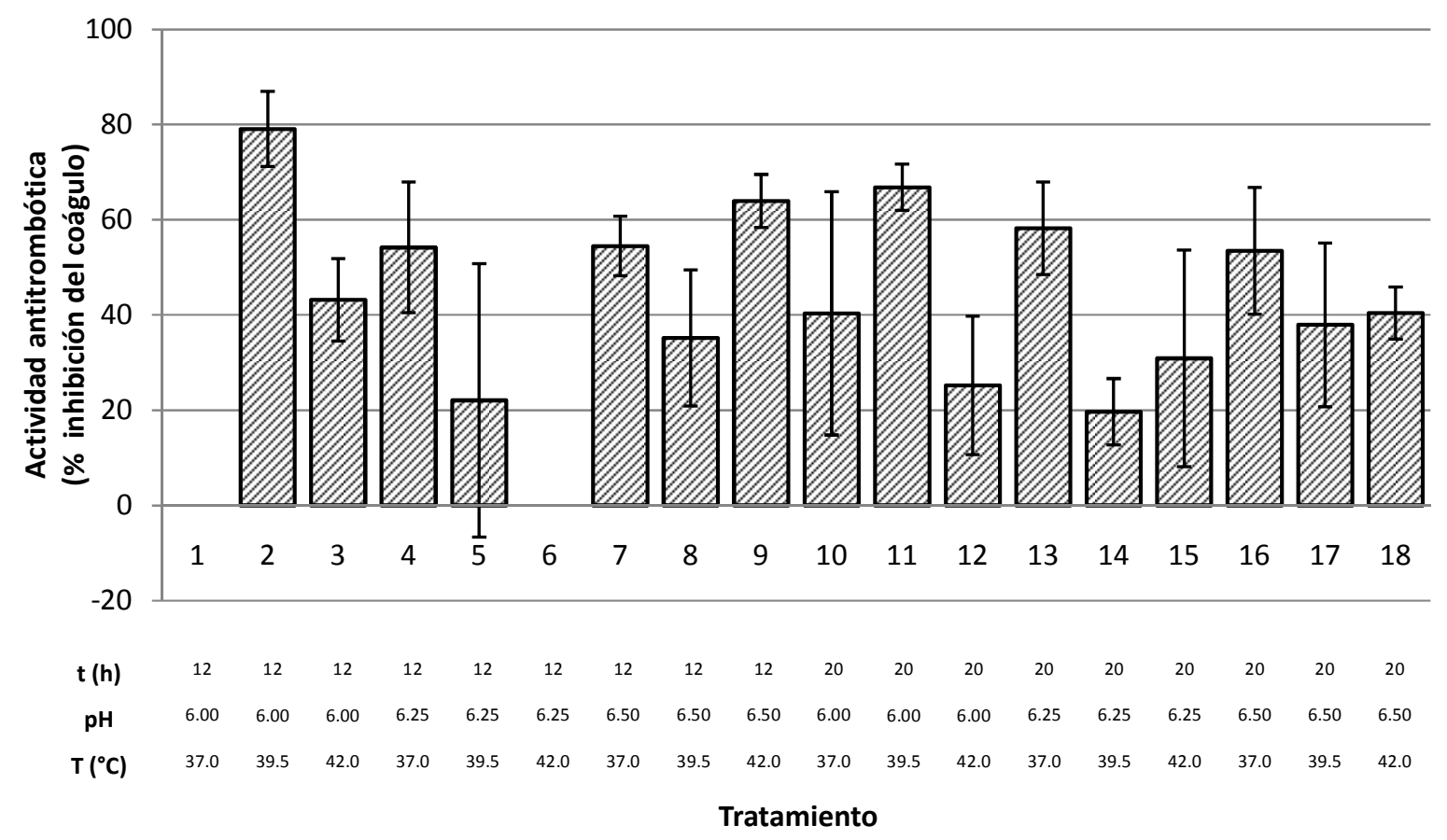

Fig. 7. Actividad antitrombótica para las muestras de los diferentes tratamientos

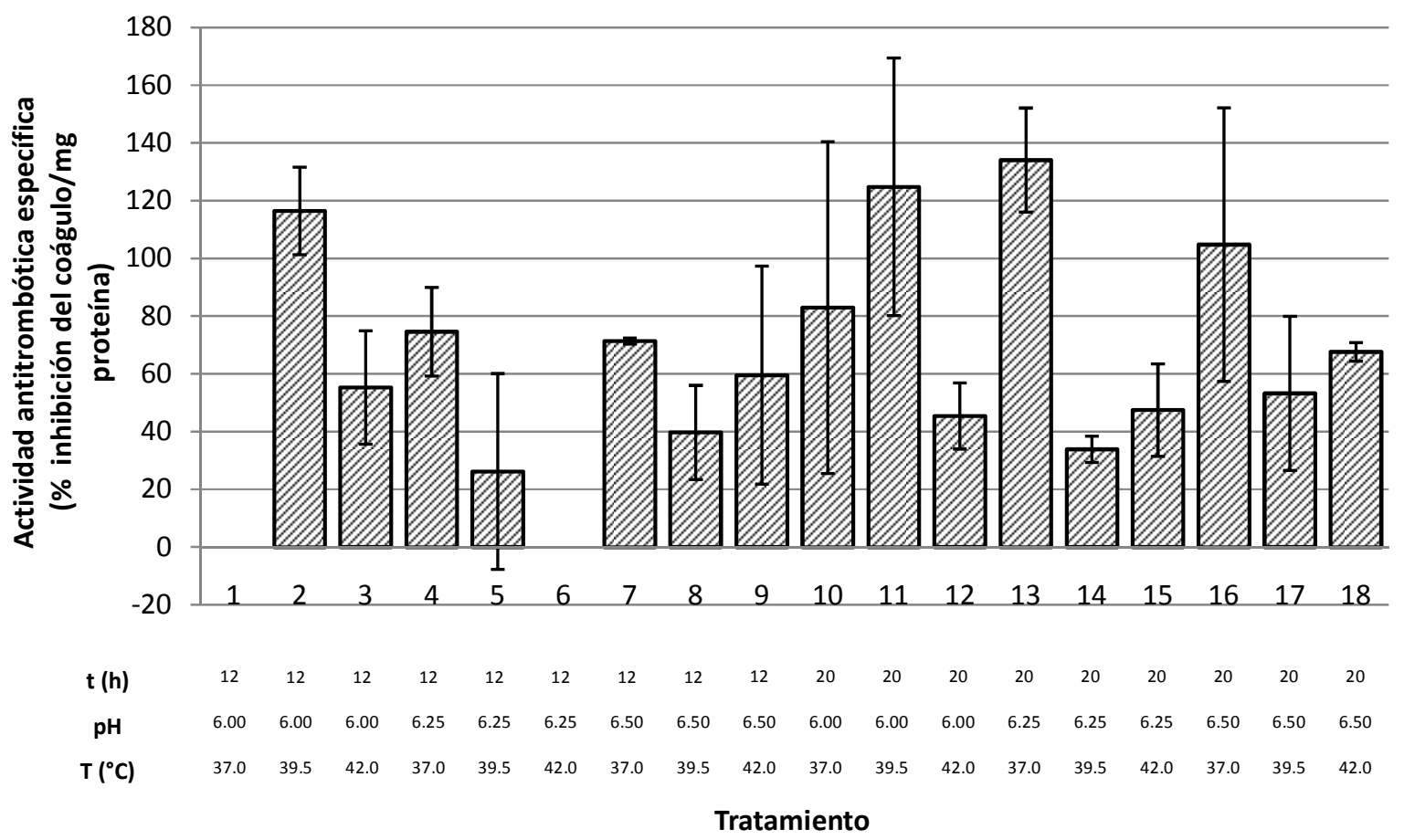

Fig. 8. Actividad específica antitrombótica para las muestras de los diferentes tratamientos 
Con el fin de conocer si las condiciones de proceso tuvieron influencia sobre la actividad específica, se realizó un análisis de varianza $(\alpha=0.05)$. En este análisis se omitieron los tratamientos 10, 11 y 16 (los cuales presentaron las mayores desviaciones estándar) para evitar que los intervalos de confianza de todos los tratamientos se traslaparan. Los resultados del análisis de varianza mostraron que al aplicar los tratamientos 2, 4, 7, 13 y 18 se obtuvo la mayor actividad antitrombótica éstos corresponden a la combinación de tratamientos $\mathrm{pH} 6.0 / 39.5{ }^{\circ} \mathrm{C} / 12 \mathrm{~h}, \mathrm{pH} 6.25 / 37$ ${ }^{\circ} \mathrm{C} / 12$ h, pH 6.5/37 ${ }^{\circ} \mathrm{C} / 12$ h, pH $6.25 / 37$ 'C/20 h y $\mathrm{pH} \quad 6.5 / 42 \quad \mathrm{C} / 20$ h, respectivamente, y los valores de actividad antitrombótica fueron 116.44, 74.63, $71.42,134.05$ y $67.64 \%$ de inhibición por mg de proteína en la reacción, respectivamente. Tanto en el caso de la actividad fijadora de hierro como en el de la actividad antitrombótica específica, destacan los tratamientos 2 ( $\mathrm{pH} \mathrm{6.0/39.5} \mathrm{C} / 12 \mathrm{~h}$ ) y 18 ( $\mathrm{pH} \mathrm{6.5/42} \mathrm{C} / 20 \mathrm{~h}$ ), los cuales se encuentran dentro de los que presentaron mayor actividad en ambos casos, este hecho podría indicar una relación entre ambas bioactividades. Por su parte, en la literatura revisada no se reporta ninguna correlación entre la actividad fijadora de hierro y antitrombótica. Por otro lado, podría tratarse de algún péptido que manifieste ambas bioactividades, para lo cual se sugiere profundizar en el estudio de estas condiciones de fermentación aunado a la purificación y secuenciación de estos péptidos. Algunos autores han reportado péptidos con múltiples funciones. Rojas-Ronquillo y col. (2012) reportaron un péptido con función antitrombótica y antihipertensiva (secuencia de aminoácidos YQEPVLGPVRGPFPIIV) proveniente de la $\beta-C N$.

En las figuras 9, 10 y 11 se presenta una serie de gráficas para analizar cada uno de los factores estudiados ( $\mathrm{pH}$, temperatura y tiempo de fermentación) de manera independiente. Para afirmar si existe o no una diferencia entre aplicar un nivel $u$ otro de cada factor en estudio, se recurrió a una análisis de varianza $(\alpha=0.05)$.

Al mantener fijo el tiempo de fermentación en 12 horas (Fig. 9-A), a pH 6.0 se observó la mayor actividad a $39.5^{\circ} \mathrm{C}$ y a valores de $\mathrm{pH}$ de 6.25 y 6.5 no hubo diferencia estadística ( $\alpha=0.05$ ) entre aplicar cualquiera de las tres temperaturas.

Al mantener el tiempo fijo en 20 horas (Fig. 9-B), a pH 6.25 la actividad fue mayor a 
$37^{\complement} \mathrm{C}$. De igual manera no se encontró diferencia si gnificativa $(\alpha=0.05)$ en el efecto de la temperatura a pH $6.0 \mathrm{ni}$ a $\mathrm{pH} 6.5$.

Al mantener la temperatura fija en $37^{\circ} \mathrm{C}$ (Fig. 10-A), $39.5^{\circ} \mathrm{C}$ (Fig. 10-B) y $42^{\circ} \mathrm{C}$ (Fig. 10-C), no se encontró diferencia significativa $(\alpha=0.05)$ en el efecto del tiempo de fermentación en ninguno de los valores de $\mathrm{pH}$ estudiados.

Al mantener fijo el tiempo en 12 horas (Fig. 11-A), a $37^{\circ} \mathrm{C}$ la actividad inició en un valor cero a pH 6.0 y posteriormente aumentó sin haber diferencia entre las actividades a los pH subsecuentes (6.25 y 6.5). A las temperaturas de 37 y $42^{\circ} \mathrm{C}$, estadísticamente $(\alpha=0.05)$ no hubo efecto del $\mathrm{pH}$ sobre la actividad.

Al mantener fijo el tiempo en 20 horas (Fig. 11-B), no hubo efecto del pH sobre la actividad a ninguna de las temperaturas estudiadas.

Con base en lo anterior se concluye que la combinación de las tres variables temperatura, tiempo y $\mathrm{pH}$ sí tiene un efecto sobre la actividad antitrombótica. Este efecto es favorable para el incremento de la actividad antitrombótica en los tratamientos 2, 4, 7, 13 y 18 .

Rutherfurd y Gill (2000) reportaron que el glicomacropéptido de la k-caseína es capaz de inhibir a la trombina en un 50\% a una concentración de $10 \mu \mathrm{M}$. Asimismo, otros péptidos como el KRDS de la lactoferrina humana son capaces de inhibir la formación de coágulos plaquetarios en un $55 \pm 10 \%$, con una concentración del péptido de $750 \mu \mathrm{M}$. Estos dos péptidos son reportados también por varios autores (Erdmann y col., 2008; Fiat y col., 1993; Jollès y col. 1986).

Hay pocos reportes en la literatura de otros péptidos derivados de la leche con propiedades inhibitorias de la trombina, sin embargo se ha encontrado actividad en péptidos derivados de la K-caseína por ejemplo los péptidos con secuencias KNQDK y IAIPPKKIQDK provenientes de la K-caseína (Chabance y col., 1995). 

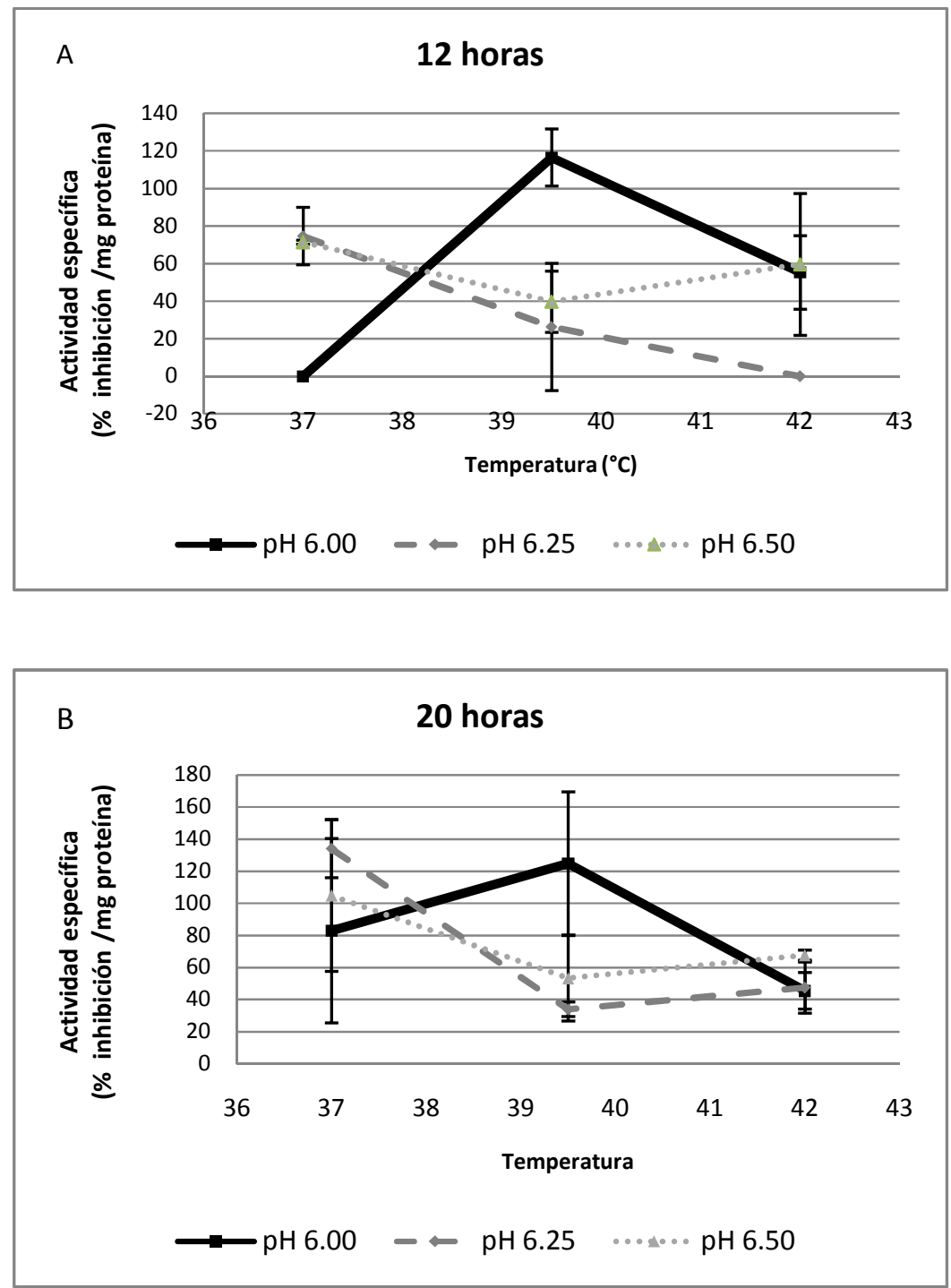

Fig.9. Actividad antitrombótica específica en función de la temperatura a (A) 12 horas y (B) 20 horas. 

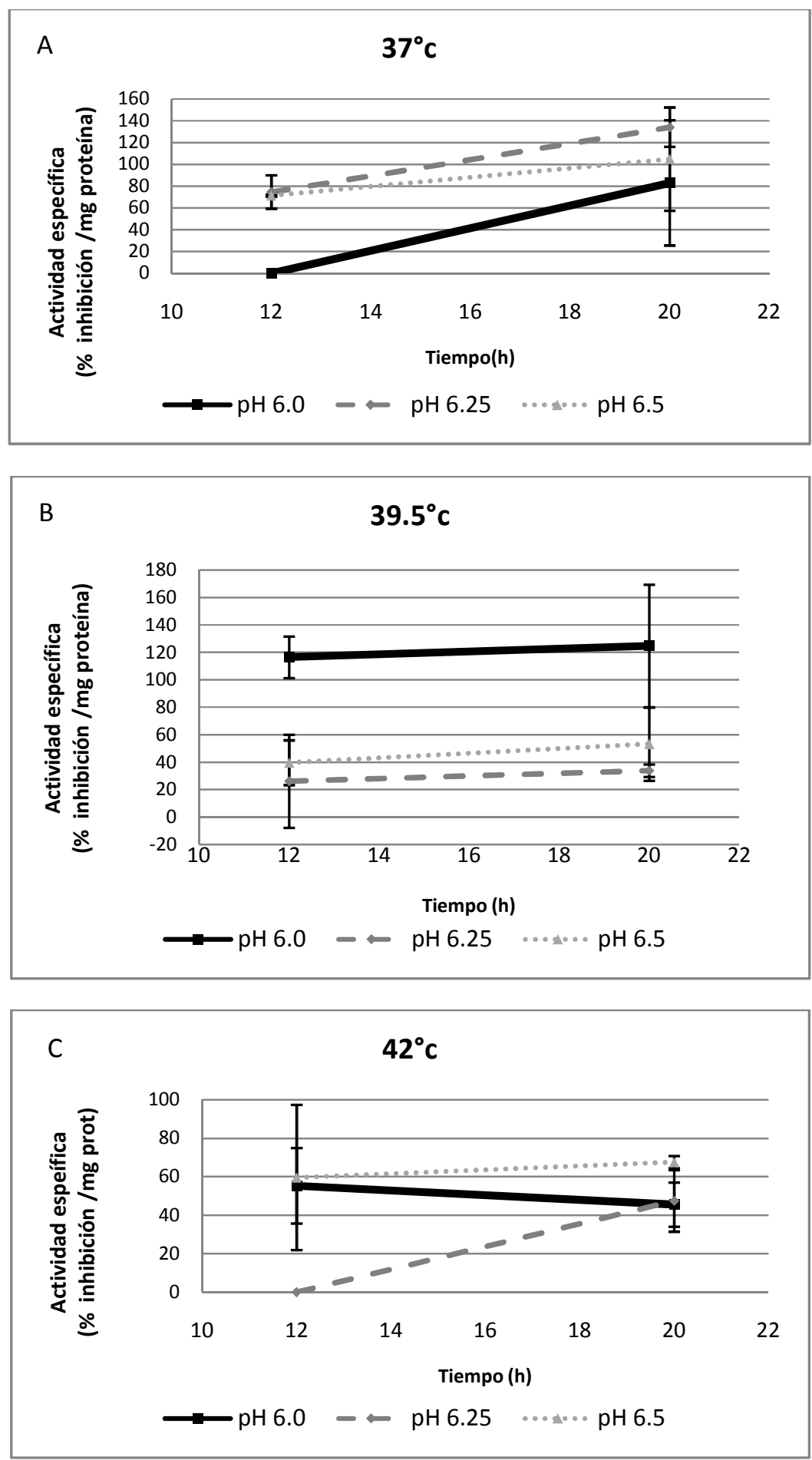

Fig.10. Actividad antitrombótica específica en función del tiempo de fermentación a (A) $37 \stackrel{\circ}{\circ}$, (B) 39.5 $\stackrel{\circ}{\circ}$ y $(C) 42 \stackrel{\circ}{\circ}$. 

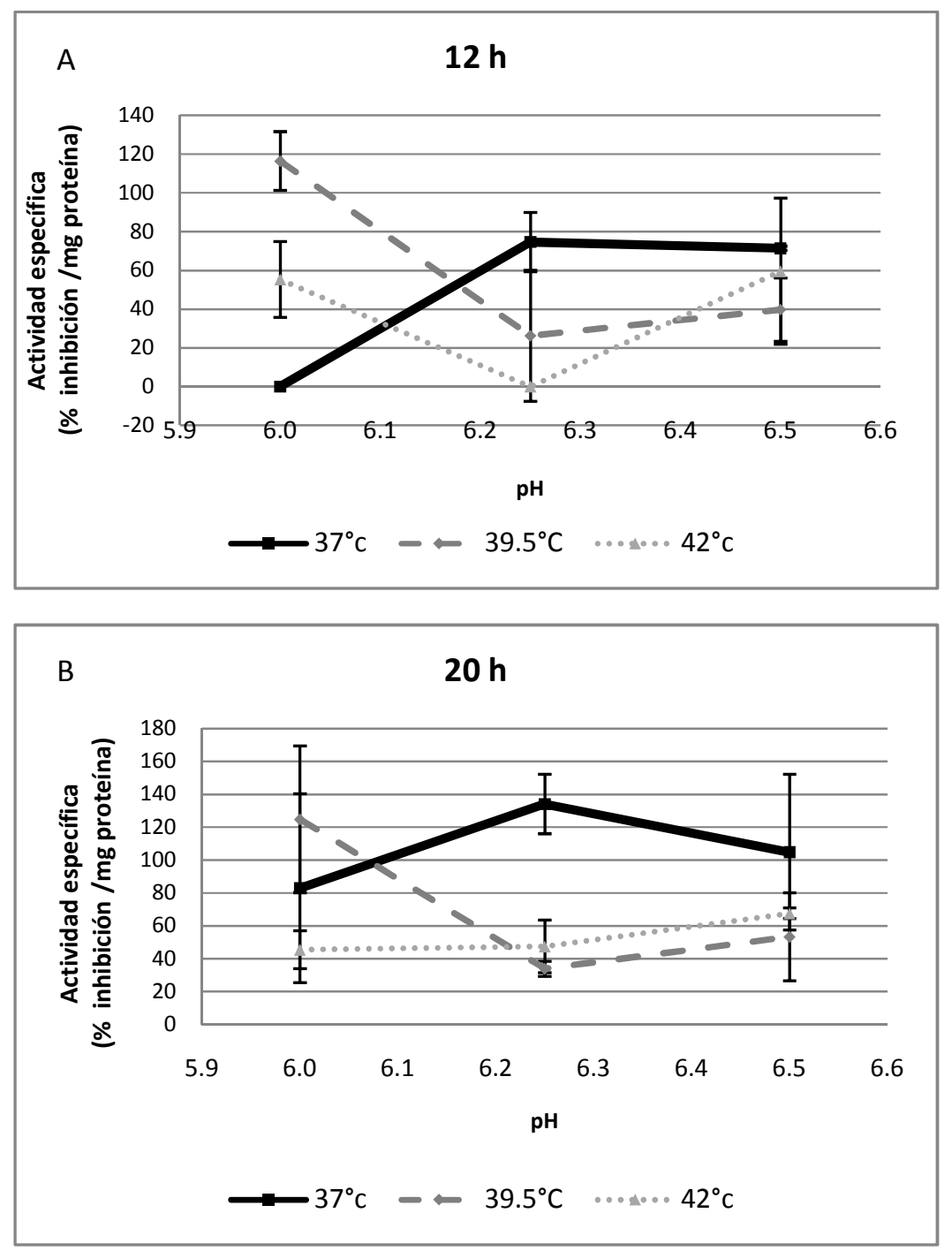

Fig.11. Actividad antitrombótica específica en función del pH a (A) 12 horas y (B) 20 horas. 


\subsection{ACTIVIDAD FIJADORA DE CALCIO}

Se determinó la actividad fijadora de calcio de los 18 tratamientos aplicados por duplicado. Los resultados de actividad se presentan en la figura 12. Con la finalidad de conocer si las condiciones de proceso tuvieron influencia sobre la actividad, se realizó un análisis de varianza de una vía $(\alpha=0.05)$. Los resultados del análisis mostraron que no hubo diferencia significativa entre tratamientos, sobre la capacidad de fijar calcio. Estos resultados obtenidos pueden estar relacionados con las desviaciones estándar de los ensayos. Estas desviaciones fueron tales que los intervalos de confianza se traslaparon en todos los tratamientos. Un factor que pudo influenciar estos resultados, fue pretratamiento de la muestra. El pretratamiento para los ensayos de fijación de hierro y de calcio, siguieron un procedimiento diferente. Mientras que para el análisis de fijación de hierro se alcalinizaron las muestras a 9.2 y centrifugaron $(10,000 \mathrm{rpm} / 30 \mathrm{~min}$ ), las de calcio se acidificaron con ácido tricloroacético al $80 \%$, se centrifugaron $(10,000 \mathrm{rpm} / 30 \mathrm{~min})$ y reajustó el pH a 8.0 de acuerdo a lo reportado por Figueroa-Hernández y col. (2012). Aún cuando las muestras de origen fueron las mismas para los dos análisis de fijación de minerales, en el ensayo de fijación de hierro sí se observaron diferencias significativas, a diferencia de los ensayos de fijación de calcio. La precipitación de algunos péptidos durante el reajuste de $\mathrm{pH}$ a la muestra pudo haber interferido con la fijación de calcio en los duplicados experimentales. Una alternativa para disminuir esta variación podría ser precipitando con una menor cantidad de ácido y efectuar el análisis sin el ajuste de $\mathrm{pH}$.

Los valores de actividad obtenidos van de 0.11 a $2.04 \mathrm{mmol}$ de Calcio fijado/mg de proteína, lo cual coincide con los resultados de Kim y col. (2004), quienes reportan actividades hasta de $2 \mathrm{mmol}$ de $\mathrm{Ca}^{2+}$ fijado por $\mathrm{mg}$ de proteína, al utilizar concentraciones de $\mathrm{CaCl}_{2}$ de hasta $8 \mathrm{mM}$.

Por su parte Figueroa-Hernández y col. (2012) reportan actividades entre 0.05 y 0.30 mmol de $\mathrm{Ca}^{2+}$ fijado por $\mathrm{mg}$ de proteína, valores más bajos que algunos de los obtenidos en el presente trabajo; en el caso de Figueroa-Hernández y col. se estudió 
leche fermentada con Lactococcus lactis.

El no apreciar una diferencia significativa entre los resultados de actividad puede atribuirse a las desviaciones estándar, las cuales son suficientemente amplias como para ocasionar que los intervalos de confianza se traslapen para todos los tratamientos. Pese a que las muestras destinadas al análisis de fijación de hierro y al de calcio provinieron originalmente de las mismas fermentaciones, el pre tratamiento para el análisis de fijación de calcio fue diferente: las muestras destinadas al análisis de hierro se alcalinizaron a 9.2 y se centrifugaron (10,000 rpm/ $30 \mathrm{~min})$, mientras las de calcio se acidificaron con ácido tricloroacético al $80 \%$, se centrifugaron $(10,000$ rpm/ $30 \mathrm{~min}$ ) y reajustó el $\mathrm{pH}$ a 8.0 de acuerdo a lo reportado por FigueroaHernández y col. (2012). Sin embargo, a pesar de que se realizó el pre tratamiento de las muestras, se obtuvieron variaciones importantes en el análisis. Otra causa de esta variación pudo ser que durante el reajuste de $\mathrm{pH}$ a la muestra la precipitación de algunos péptidos pudiera haber interferido con la fijación de calcio de manera distinta en los duplicados experimentales. Una alternativa para disminuir esta variación podría ser precipitando con una menor cantidad de ácido y efectuar el análisis sin el ajuste de $\mathrm{pH}$.

Kim y col. (2004) reportan actividades hasta de $2 \mathrm{mmol}$ de $\mathrm{Ca}^{2+}$ fijado por miligramo de proteína, al utilizar concentraciones de $\mathrm{CaCl}_{2}$ de hasta $8 \mathrm{mM}$.

Figueroa-Hernández y col. (2012) reportan actividades entre 0.05 y $0.30 \mathrm{mmol}$ de $\mathrm{Ca}^{2+}$ fijado por miligramo de proteína, en este caso se estudiaron hidrolizados de Lactococcus lactis. 


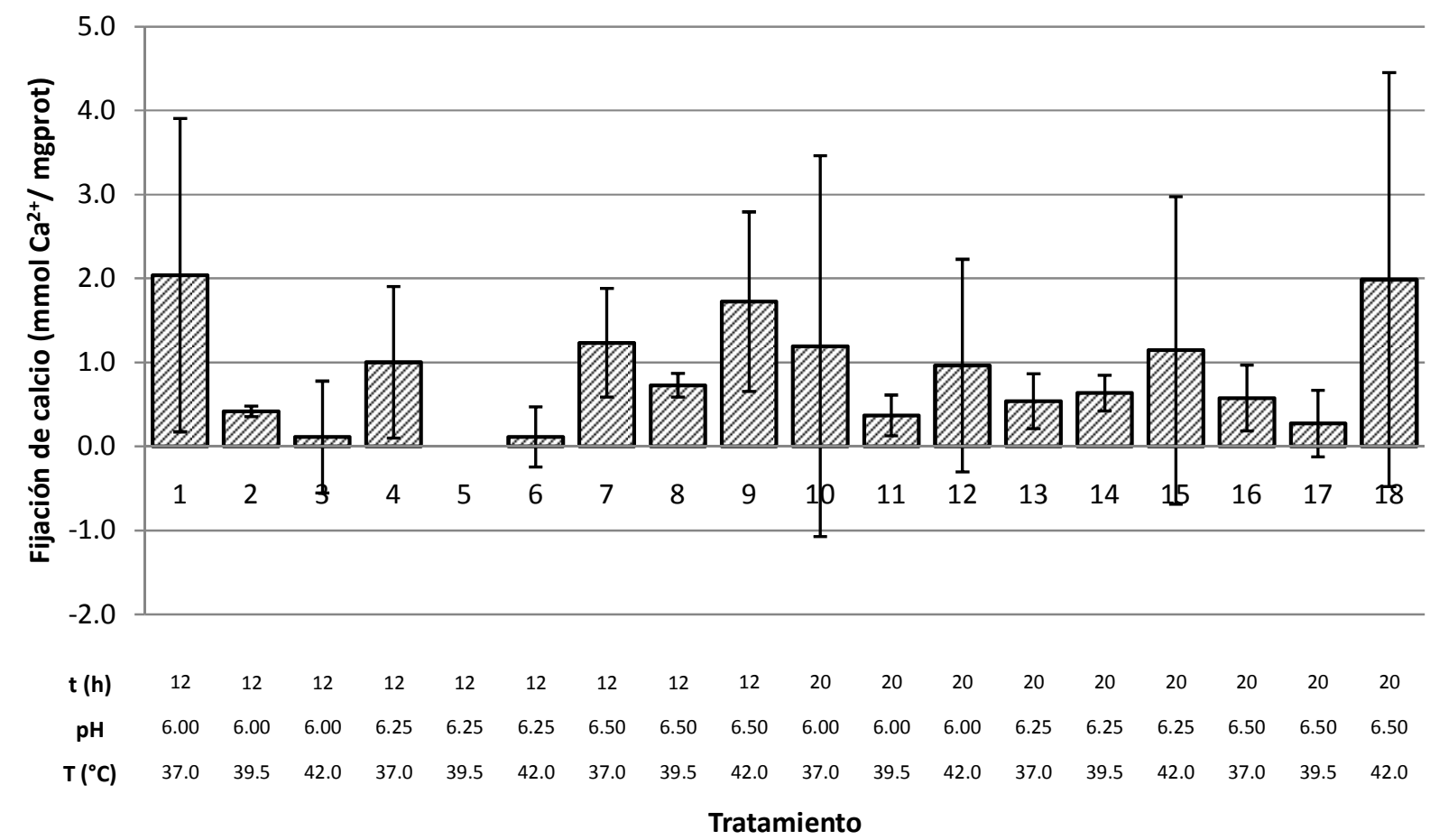

Fig. 12. Actividad fijadora de calcio para las muestras de los diferentes tratamientos 


\section{CONCLUSIONES}

Lactobacillus casei Shirota fue capaz de producir fracciones peptídicas antitrombóticas y fijadoras de hierro a diferentes condiciones de fermentación. Se comprobó que la combinación de $\mathrm{pH}$, temperatura y tiempo de fermentación sí tienen una influencia sobre la producción de péptidos fijadores de hierro y antitrombóticos.

La máxima actividad fijadora de hierro se encontró con las siguientes combinaciones: a las 12 horas, las combinaciones pH 6.0/42 ${ }^{\circ} \mathrm{C}, \mathrm{pH} 6.25 / 42 \stackrel{\circ}{\circ} \mathrm{C}, \mathrm{pH}$ 6.0/39.5 ${ }^{\circ} \mathrm{C}$ y a las 20 horas, $\mathrm{pH} 6.5 / 42^{\circ} \mathrm{C}$; con valores de actividad de entre $2.35 \cdot 10^{-}$ ${ }^{4}$ y $4.62 \cdot 10^{-4} \mathrm{mmol}$ de $\mathrm{Fe}^{2+}$ fijado por $\mathrm{mg}$ de proteína.

Destacó la temperatura de $42{ }^{\circ} \mathrm{C}$ en la actividad fijadora de hierro, temperatura óptima de actividad de la proteinasa de pared celular de Lactobacillus casei Shirota.

La máxima actividad antitrombótica se encontró con las siguientes combinaciones: a las 12 horas de fermentación, las combinaciones $\mathrm{pH}$ 6.0/39.5 ${ }^{\circ} \mathrm{C}, \mathrm{pH} 6.25 / 37^{\circ} \mathrm{C}, \mathrm{pH}$ $6.5 / 37^{\circ} \mathrm{C}$, y a las 20 horas de fermentación, las combinaciones $\mathrm{pH} 6.25 / 37^{\circ} \mathrm{C}$ y $\mathrm{pH}$ 6.5/42 ํㅜ ; con porcentajes de inhibición de entre 67.6 y $134.0 \%$ de inhibición de coágulo por mg de proteína. Se observó la influencia de la temperatura como factor independiente, con máximo de actividad antitrombótica a $39.5{ }^{\circ} \mathrm{C}$, únicamente cuando el pH fue de 6.0, tanto a 12 como a 20 horas de fermentación.

Se encontraron valores de actividad fijadora de calcio de 0.11 a $2.04 \mathrm{mmol}$ de $\mathrm{Ca}^{2+}$ fijado por $\mathrm{mg}$ de proteína. Las condiciones del proceso estudiadas no tuvieron influencia sobre la producción de péptidos fijadores de calcio. 


\section{Perspectivas}

Como una mayor aproximación para encontrar los tratamientos que produzcan más péptidos, es necesario estudiar otros factores del proceso, sobre todo en aquellas fermentaciones cuyos productos presentaron mayor actividad.

A fin de enriquecer la información existente sobre los péptidos fijadores de hierro y antitrombóticos, es necesario purificar e identificar a los péptidos presentes en las fermentaciones con mayores actividades. 


\section{RefERENCIAS}

1. Ahn, J.E., Park, S. Y., Atwal, A., Gibbs, B. F. \& Lee, B. H. (2009). Angiotensin Iconverting enzyme (ACE) inhibitory peptides from whey fermented by lactobacillus species. Journal of Food Biochemistry. 33: 587-602

2. Brandsaeter, E. \& Nelson, F. E. (1955). Proteolysis by Lactobacillus casei. I. Proteinase activity. lowa Agricultural Experiment Station, Ames, lowa.72: 68-72.

3. Boutrou, R., Molle, D. \& Léonil, J. (2001). Action of the lactoccocal proteinase during Camembert-type curd making. International Dairy Journal. 11: 347-354.

4. Chabance, B., Jollès, P., Izquierdo, C., Mazoyer, E., Francoual, C. Drouet, Ludovic., Fiat., A. M. (1995). Characterization of an antitrombotic peptide from k-casein in newborn plasma after milk ingestion. British Journal of Nutrition. 73: 583-590.

5. Dimitrov, Z. (2009). Characterization of bioactive peptides with calcium-binding activity released by specially designed cheese starter. Biotechnology and Biotechnological Equipment. 23: 927-930.

6. Erdmann, K., Cheung, B. W. Y. \& Schröder, H. (2008). The possible roles of foodderived bioactive peptides in reducing the risk of cardiovascular disease. Journal of Nutritional Biochemistry. 19: 643-645.

7. Farvin, K. H. S., Baron, C. P., Nielsen, N. S. \& Jacobsen, C. (2010). Antioxidant activity of yoghurt peptides: Part 1-in vitro assays and evaluation in $\omega$-3 enriched milk. Food Chemistry 123 (2010) 1081-1089

8. Fernandez-Espla, M. D., Garault, P., Monnet, V. \& Rul, F. (2000). Streptococcus thermophilus cell wall-anchored proteinase: Release, purification, and biochemical and genetic characterization. Applied and Environmental Microbiology. 66: 47724778.

9. Fernández de Palencia, P., Peláez, C., Romero, C., \& Martín-Hernández, M. C. (1997).Purification and characterization of the cell wall proteinase of Lactobacillus casei subsp. casei IFPL 731 isolated from raw goat's milk cheese. Journal of Agricultural Food Chemistry. 45: 3401-3405.

10. Fiat, A. M., Migliore- Samour, D., Jollès, P., Drouet, L., Dit Solier, C. B. \& Caen, J. (1993). Biological active peptides from milk proteins with emphasis on two examples concerning antithrombotic and immunomodulating activities. Journal of Dairy science. 
76: 301-320.

11. Figueroa-González, I. (2010). Estudio de prebióticos en el crecimiento de bacterias probióticas comerciales y en la síntesis de compuestos con actividad antimicrobiana Tesis de doctorado. México, D. F. Universidad Autónoma Metropolitana unidad Iztapalapa. 77 pp.

12. Figueroa-González, I., Quijano, G., Ramírez, G. \& Cruz-Guerrero, A. (2011). Probiotics and prebiotics - perspectives and challenges. Journal of Science Food Agriculture. 91: 1341-1348.

13. Figueroa-Hernández, C., Cruz-Guerrero, A., Rodríguez-Serrano, G., Gómez-Ruiz, L., García-Garibay, M. \& Jiménez-Guzmán, J. (2012). Calcium and iron binding peptides production by Lactococcus lactis subsp. cremoris NCFB 712. Revista Mexicana de Ingeniería Química. 11:259-267.

14. Fuglsang, A., Rattray, F. P., Nilsson, D. \& Nyborg, N. C. B. (2003). Lactic acid bacteria: inhibition of angiotensin converting enzyme in vitro and in vivo. Antonie van Leeuwenhoek. 83: 27-34.

15. Ghassem, M., Arihara, K., Babji, A. S., Said, M. \& Ibrahim, S. (2011) Purification and identification of ACE inhibitory peptides from Haruan (Channastriatus) myofibrillar protein hydrolysate using HPLC-ESI-TOF MS/MS. Food Chemistry. 129: 1770-1777.

16. Gobbetti, M., Lanciottia, R., De Angelis M., Corboa, M, R. Massinia, R. \& Fox, P. (1999).Study of the effects of temperature, $\mathrm{pH}, \mathrm{NaCl}$, and $\mathrm{a}_{\mathrm{w}}$ on the proteolytic and lipolytic activities of cheese-related lactic acid bacteria by quadratic response surface methodology. Enzyme and Microbial Technology. 25: 795-809.

17. González-Olivares, G., Jiménez-Guzmán, J., Cruz-Guerrero, A., Rodríguez-Serrano, G., Gómez-Ruiz, L. \& García-Garibay, M. (2011). Liberación de péptidos bioactivos por bacterias ácido lácticas en leches fermentadas comerciales. Revista Mexicana de Ingeniería Química. 10: 179-188.

18. Gonzalez-Gonzalez, C. R., Tuohy, K M. \& Jauregi, P. (2011).Production of angiotensin-I-converting enzyme (ACE) inhibitory activity in milk fermented with probiotic strains: Effects of calcium, $\mathrm{pH}$, and peptides on the ACE-inhibitory activity. International Dairy Journal. 21: 615-622.

19. Guangrong, H., Lie, R. \& Jiaxin, J. (2011). Purification of a histidine-containing peptide with calcium binding activity from shrimp processing byproducts hydrolysate. European Food Research Technology. 232: 281-287. 
20. Guesdon, B., Messaoudi, M., Lefranc-Millot, C., Fromentin, G., Tomé, D. \& Even, P. C. (2006). A tryptic hydrolysate from bovine milk $\alpha s_{1}$-casein improves sleep in rats subjected to chronic mild stress. Peptides. 27: 1476-1482.

21. Guo, Y., Pan, D. \& Tanokura, M. (2009). Optimization of hydrolysis conditions for the production of the angiotensin-I converting enzyme (ACE) inhibitory peptides from whey protein using response surface methodology. Food Chemistry. 114: 328-333.

22. Hartmann, R. \& Meisel, H. (2007). Food-derived peptides with biological activity: from research to food applications. Current Opinion in Biotechnology. 18: 163-169.

23. Hickson, M. (2011). Probiotics in the prevention of antibiotic-associated diarrhea and Clostridium difficile infection. Therapeutic Advances in Gastroenterology. 4: 185-197.

24. Iwaniak, A. \& Minkiewicz, P. (2008). Biologically active peptides derived from proteins - A review. Polish Journal of Food and Nutrition Sciences. 58: 289-294.

25. Jollès, P., Levy-Toledano, S., Fiat, A. M., Soria, C., Gillessen, D., Thomaidis, A., Dunn, F. W. \& Caen, J. P. (1986). Analogy between fibrinogen and casein. Effect of an undecapeptide isolated from kappa-casein on platelet function. European Journal of Biochemistry. 158: 379-82.

26. Juillard, V., Laan, H., Kunji, E. R. S., Jeronimus-Stratingh, M., Bruins, A. P. \& Konings, W. L. (1995). The extracellular $P_{\mathrm{i}}$-type proteinase of Lactococcus lactis hydrolyzes Bcasein into more than one hundred different oligopeptides. Journal of Bacteriology. 177: 3472-3478.

27. Kim, S. B., Shin, H. S. \& Lim, J. W. (2004). Separation of calcium-binding protein derived from enzymatic hydrolysates of cheese whey protein. Asian-Australasian Journal of Animal Sciences . 17: 712-718.

28. Korhonen, H. (2009). Milk-derived bioactive peptides: from science to applications. Journal of Functional Foods. 1: 177-187.

29. Korhonen, H. \& Pihlanto, A. (2006). Bioactive peptides: Production and functionality. International Dairy Journal. 16: 945-960

30. Kojic, M., Fira, D., Banina, A. \& Topisirovic, L. (1991). Characterization of the Cell Wall- Bound Proteinase of Lactobacillus casei HN14. Applied and Environmental Microbiology. 57: 1753-1757.

31. López-Fandiño, R. ,Otte, J. \& van Camp, J. (2006). Physiological, chemical and technological aspects of milk-protein-derived peptides with antihypertensive and ACEinhibitory activity. International Dairy Journal. 16: 1277-1293. 
32. Lowry O., Rosebrough N. \& Farr A., Randall R. (1951). Protein measurement with the Folin phenol reagent. Journal of Biology and Chemistry. 193: 265-275.

33. Manso, M. A., Léonil, J., Piot, M. \& Gagnaire, V. (2005). Isolation and characterization of a Lactobacillus helveticus ITG LH1 peptidase-rich sub-proteome. International Journal of Food Microbiology. 105: 119-129.

34. Meijer, W., Marugg, J. D., \& Hugenholtz, J. (1996). Regulation of proteolytic enzyme activity in Lactococcuslactis. Applied and environmental microbiology. 62: 156-161.

35. Nielsen, M. S., Martinussen, T., Flambard, B., Sørensen, K. I. \& Otte, J. (2009). Peptide profiles and angiotensin-l-converting enzyme inhibitory activity of fermented milk products: Effect of bacterial strain, fermentation $\mathrm{pH}$, and storage time, International Dairy Journal. 19: 155-165.

36. Ogawa, M., Shimizu, K., Nomoto, K., Takhashi, M., Watanuki, M., Tanaka R., Tanaka, T., Hamabata, T., Yamasaki, S. \& Takeda, Y. (2001). Protective effect of Lactobacillus casei Strain Shirota on shiga toxin-producing Escherichia coli O157:H7 infection in infant rabbits. Infection and Immunity. 69: 1101-1108.

37. Ong, L., Henrikkson, A. \& Shah, N. P. (2007). Angiotensin converting enzymeinhibitory activity in Cheddar cheeses made with the addition of probiotic Lactobacillus casei sp. Dairy Science and Technology. 87: 149-165.

38. Otte, J., Lenhard, T., Flambard, B. \& Sørensen, K. I. (2011). Influence of fermentation temperature and autolysis on ACE-inhibitory activity and peptide profiles of milk fermented by selected strains of Lactobacillus helveticus and Lactococcus lactis. International Dairy Journal. 21: 229-238.

39. Pan, D. \& Guo, Y. (2010). Optimization of sour milk fermentation for the production of ACE-inhibitory peptides and purification of a novel peptide from whey protein hydrolysate. International Dairy Journal. 20: 472-479.

40. Pihlanto, A., Virtanen, T. \& Korhonen, H. (2010). Angiotensin I converting enzyme (ACE) inhibitory activity and antihypertensive effect of fermented milk. International Dairy Journal. 20: 3-10.

41. Ramachandran, L. \& Shah, N. P. (2008). Proteolytic profiles and angiotensin-I converting enzyme and a-glucosidase inhibitory activities of selected lactic acid bacteria. Journal of Food Science. 73: M75-M81.

42. Reid, J. R. \& Coolbear, T. (1998).Altered specificity of lactococcal proteinase $P_{1}$ (lactocepin I) in humectant systems reflecting the water activity and salt content of 
cheddar cheese. Applied and Environmental Microbiology. 64: 588-593.

43. Rojas-Ronquillo, R. (2012) Péptidos bioactivos de suero de leche y caseínas, liberados por la actividad proteolítica de Lactobacillus casei Shirota y Streptococcus thermophilus. Tesis de doctorado. México, D. F. Universidad Autónoma Metropolitana unidad Iztapalapa. 59 pp.

44. Rojas-Ronquillo, R., Cruz-Guerrero, A., Flores-Nájera, A., Rodríguez-Serrano, G., Gómez-Ruiz, L., Reyes-Grajeda, J. P., Jiménez-Guzmán, J. \& García-Garibay, M. (2012). Antithrombotic and angiotensin-converting enzyme inhibitory properties of peptides released from bovine casein by Lactobacillus casei Shirota. International Dairy Journal. 26: 147-154.

45. Rutherfurd, K. J. \& Gill, H. S. (2000). Peptides affecting coagulation. British Journal of Nutrition. 84: S99-S102.

46. Sadat-Mekmene, L., Genay, M., Atlan, D., Lortal, S. \& Gagnaire, V. (2011). Original features of cell-envelope proteinases of Lactobacillus helveticus. A review. International Journal of Food Microbiology. 146: 1-13.

47. Silva, S.V. \& Malcata, F. X.(2005). Caseins as source of bioactive peptides. International Dairy Journal.15:1-15.

48. Torres-Llanez, M. J., Vallejo-Córdoba, B. \& González-Córdoba, A. F. (2005). Péptidos bioactivos derivados de las proteínas de la leche. Archivos Latinoamericanos de Nutrición. 55: 111-117.

49. Ul-Haq, I. \& Mukhtar, H. (2006). Biosynthesis of protease from Lactobacillus paracasei. Kinetic Analysis of fermentation parameters. Indian Journal of Biochemistry and Biophysics. 43: 377-381.

50. Yoon, S. \& Sun, Y. (2011). Probiotics, Nuclear receptor signaling, and antiinflammatory pathways. Gastroenterology Research and Practice. 2011: 1-16.

51. Zhang, S. B., Wang, Z. \& Xu, S. Y. (2008). Antioxidant and antithrombotic activities of rapeseed peptides. Journal of the American Oil Chemists' Society. 85: 521-527. 
ESTUDIO DE PEPTIDOS

ACARREADORES DE MINERALES Y

ANTITROMBOTICOS LIBERADOS

DURANTE LA FERMENTACION DE

LECHE CON Lactobacillus

casei SHTROTA

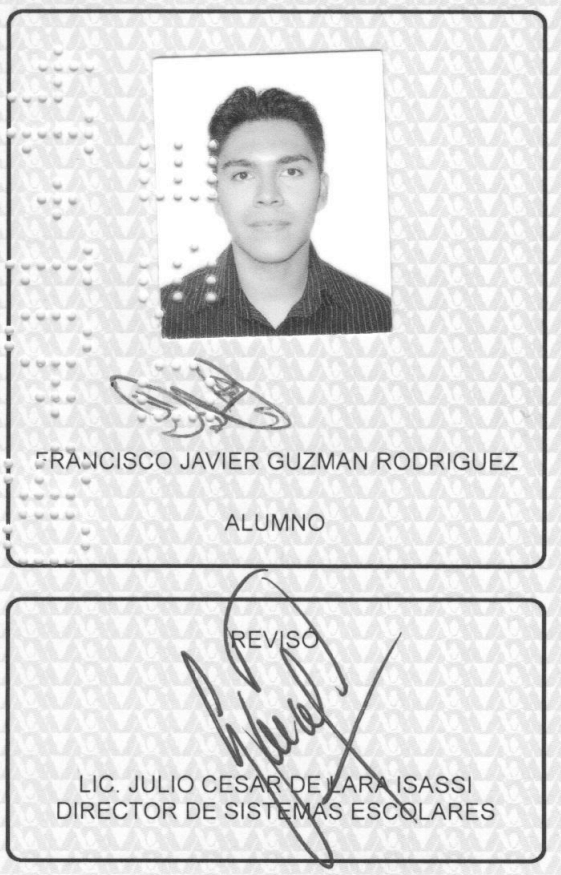

Bajo la presidencia de la primera y con carácter de Secretaria la última, se reunieron para proceder al Examen de Grado cuya denominación aparece al margen, para la obtencion del grado de:

MAESTRO EN BIOTECNOLOGIA

DE: FRANCISCO JAVIER GUZMAN RODRIGUEZ

y de acuerdo con el artículo 78 fracción III del Reglamento de Estudios Superiores de la Universidad Autónoma Metropolitana, los miembros del jurado

$$
\text { aprotar }
$$

Acto continuo, la presidenta del jurado comunicó al interesado el resultado de la evaluación y, en caso aprobatorio, le fue tomada la protesta.

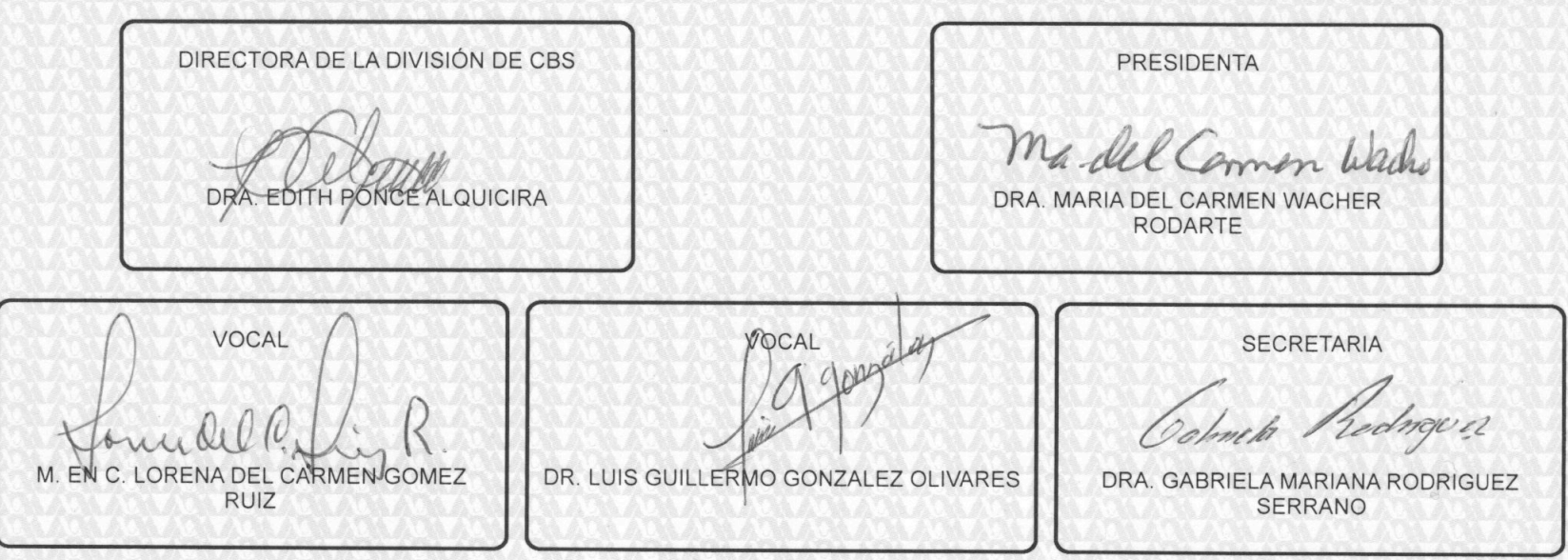

